\title{
Anterior Cingulate Cortex and Ventral Hippocampal Inputs to the Basolateral Amygdala Selectively Control Generalized Fear
}

\author{
[DSamantha Ortiz, ${ }^{1,2}$ Maeson S. Latsko, ${ }^{1,2}$ Julia L. Fouty, ${ }^{1}$ Sohini Dutta, ${ }^{1,2}$ Jordan M. Adkins, ${ }^{1,2}$ and $\oplus^{\circledR}$ Aaron M. Jasnow ${ }^{1,2}$ \\ ${ }^{1}$ Department of Psychological Sciences, and ${ }^{2}$ Brain Health Research Institute, Kent State University, Kent, OH 44242
}

A common symptom of anxiety disorders is the overgeneralization of fear across a broad range of contextual cues. We previously found that the ACC and ventral hippocampus (vHPC) regulate generalized fear. Here, we investigate the functional projections from the ACC and vHPC to the amygdala and their role in governing generalized fear in a preclinical rodent model. A chemogenetic approach (designer receptor exclusively activated by designer drugs) was used to inhibit glutamatergic projections from the ACC or vHPC that terminate within the BLA at recent $(1 \mathrm{~d})$ or remote $(28 \mathrm{~d})$ time points after contextually fear conditioning male mice. Inactivating ACC or vHPC projections to the BLA significantly reduced generalized fear to a novel, nonthreatening context but had no effect on fear to the training context. Further, our data indicate that the ACC-BLA circuit supports generalization in a time-independent manner. We also identified, for the first time, a strictly time-dependent role of the vHPC-BLA circuit in supporting remote generalized contextual fear. Dysfunctional signaling to the amygdala from the ACC or the HPC could underlie overgeneralized fear responses that are associated with anxiety disorders. Our findings demonstrate that the ACC and vHPC regulate fear expressed in novel, nonthreatening environments via projections to the BLA but do so as a result of training intensity or time, respectively.

Key words: amygdala; ACC; anxiety disorders; context generalization; DREADD; hippocampus

Significance Statement

Anxiety disorders are characterized by a common symptom that promotes overgeneralization of fear in nonthreatening environments. Dysregulation of the amygdala, ACC, or hippocampus (HPC) has been hypothesized to contribute to increased fear associated with anxiety disorders. Our findings show that the ACC and HPC projections to the BLA regulate generalized fear in nonthreatening, environments. However, descending ACC projections control fear generalization independent of time, whereas HPC projections play a strictly time-dependent role in regulating generalized fear. Thus, dysfunctional ACC/HPC signaling to the BLA may be a predominant underlying mechanism of nonspecific fear associated with anxiety disorders. Our data have important implications for predictions made by theories about aging memories and interactions between the HPC and cortical regions.

\section{Introduction}

Exposure to stressful events can precipitate anxiety disorders, which can afflict 10\%-30\% of individuals worldwide (Alonso et

Received April 10, 2019; revised May 15, 2019; accepted June 5, 2019.

Author contributions: S.O. and A.M.J. designed research; S.O., M.S.L., J.L.F., S.D., and J.M.A. performed research; S.O. analyzed data; S.O. and A.M.J. wrote the first draft of the paper; S.O., M.S.L., and A.M.J. edited the paper; S.O. and A.M.J. wrote the paper.

This work was supported in part by Whitehall Foundation Grant 2012-12-90. The Whitehall Foundation did not have any role in the design, collection, analysis, interpretation, writing, or manuscript submission process for the experiments and data described herein. We thank Dr. David Riccio, Dr. Devin Mueller, and Dr. John Johnson for intellectual contributions; Courtney Costanzo and Jasmin Beaver for research assistance in the data collection; and the animal care staff in the Department of Psychological Sciences.

The authors declare no competing financial interests.

Correspondence should be addressed to Aaron M. Jasnow at ajasnow@kent.edu.

https://doi.org/10.1523/JNEUROSCI.0810-19.2019

Copyright $@ 2019$ the authors al., 2004; Kessler et al., 2012). A debilitating symptom of many anxiety disorders is the overgeneralization of fear (Dymond et al., 2015; Morey et al., 2015), manifesting as hyperarousal across a range of contexts that are not associated with any aversive event (Lissek et al., 2005, 2010). Moreover, people with anxiety disorders have hyperreactive amygdalae (Shin et al., 2004, 2006) along with decreased ACC (Yamasue et al., 2003; Woodward et al., 2006; Asami et al., 2008; Greenberg et al., 2013) and hippocampal volumes (Gurvits et al., 1996; Shin et al., 2006; Chen and Etkin, 2013). Although these regions are associated with anxiety disorders, there is no evidence demonstrating how these brain areas interact to support overgeneralization of fear, leading to the maintenance of anxiety symptomology. In this study, we explore generalized fear, fear occurring in nonthreatening contexts, using a preclinical rodent model to identify whether glutamatergic pro- 
jections from the ACC and/or hippocampus (HPC) to the amygdala regulate generalized fear.

Rodent models of context fear learning have been used for decades to study the underlying mechanisms of fear generalization (for review see, Jasnow et al., 2012, 2017; Asok et al., 2018). Twenty-four hours after training mice to fear a context with specific cues, if placed back in the training context, mice display high levels of freezing, a fundamental rodent fear response. If mice are instead placed in a novel context that is different from the training context, they display low levels of freezing, indicating little fear to the novel context. As the time interval between training and testing increases, mice freeze in the novel context at similar levels to those in the training context, generalizing fear to the novel, nonthreatening context.

Time-dependent generalized fear is thought to rely on cortical regions (Frankland et al., 2004b; Einarsson et al., 2015), independent of the HPC, whereas fear responses to specific contexts, specific fear, are reliant on the HPC (Zola-Morgan and Squire, 1990; Frankland et al., 1998, 2004a; Teyler and Rudy, 2007; Winocur et al., 2007; Wiltgen et al., 2010). We previously identified that generalized fear is simultaneously dependent on the ACC and the ventral HPC (vHPC); inactivation of either region reduced fear in a novel, nonthreatening context but left fear to the training context unaltered (Cullen et al., 2015).

Although the ACC and HPC are implicated in anxiety disorders (see above citations) and generalized fear (Einarsson and Nader, 2012; Cullen et al., 2015; Zhou et al., 2017), little is known about the circuits through which they govern generalized fear responses. A single study found that circuits connecting the ACC and $\mathrm{vHPC}$ in the nucleus reunions are necessary for the learning of specific fear (Xu and Südhof, 2013), inactivating these circuits before training induces rapid fear generalization. However, how the ACC and vHPC outputs govern temporally graded generalized fear during recall is completely unknown. The ACC and vHPC each communicate with the BLA (Maren and Fanselow, 1995; Cenquizca and Swanson, 2007; Morozov et al., 2011), a critical region for fear acquisition and expression (Kim and Fanselow, 1992; Kim et al., 1993; Campeau and Davis, 1995; Maren et al., 1996; Schafe et al., 2005; Do-Monte et al., 2015). Thus, we hypothesize that ACC and vHPC projections converge within the BLA to regulate time-dependent contextual generalization of fear.

To identify whether ACC and vHPC projections to the BLA regulate generalized fear, we used designer receptor exclusively activated by designer drugs (DREADDs) (Armbruster et al., 2007) to selectively express the modified human muscarinic acetylcholine receptor $4(\mathrm{hM} 4 \mathrm{D})$ within the ACC or vHPC. We found new evidence that inactivation of ACC or vHPC projections in the BLA dramatically attenuated generalized fear in timeindependent and time-dependent processes, respectively; specific fear was unaltered. Our findings suggest that overgeneralization of fear in people with anxiety disorders may result from hyperreactive amygdalae due to dysfunctional signaling from the ACC or HPC.

\section{Materials and Methods}

Subjects. Experiments 1 (see Fig. 1B), 2 (see Fig. $1 C-G$ ), 3 (see Fig. 2), 5 (see Fig. 4), and 6 (see Fig. 5) used 224 C57BL/6J male mice. Experiments 4 (see Fig. 3) and 7 (see Fig. 6) used 87 F1 male hybrids generated from crossing C57BL/6 males and 129S1/SvImJ females (The Jackson Laboratory). All mice were generated from a breeding colony in the Department of Psychological Sciences at Kent State University. Mice were 5-7 weeks of age before they were used for experimentation and were group housed
(2-5 mice per cage) with free access to food and water in a room maintained on a 12:12 light/dark cycle. All procedures were conducted in a facility accredited by the American Association for Laboratory Animal Care, in accordance with the National Institutes of Health guidelines, and with approval by Kent State University Institutional Animal Care and Use Committee guidelines.

Surgical procedures. Mice were anesthetized with a subcutaneous injection of a ketamine $(75 \mathrm{mg} / \mathrm{kg})+$ xylazine $(10 \mathrm{mg} / \mathrm{kg})+$ acepromazine $(2$ $\mathrm{mg} / \mathrm{kg}$ ) mixture. Following administration of anesthesia, mice were mounted on a stereotaxic apparatus (David Kopf Instruments). The scalp of each mouse was retracted; the skull was adjusted so that bregma and lambda were on the same horizontal plane (within $0.05 \mathrm{~mm}$ of each other). Two 0.33-gauge infusion needles were guided to the appropriate coordinates relative to bregma, and small bilateral burr holes were drilled. Coordinates for the brain regions were as follows: ACC, $0.08 \mathrm{~mm}$ $\mathrm{AP}, \pm 0.07 \mathrm{~mm} \mathrm{ML},-3.6 \mathrm{~mm}$ DV from bregma at a $14^{\circ}$ angle; vHPC, $-3.2 \mathrm{~mm} \mathrm{AP}, \pm 3.3 \mathrm{~mm} \mathrm{ML},-4.25 \mathrm{~mm}$ DV from bregma. AAV8CaMKIIa-hM4D(Gi)-mCherry virus (hM4D) (Addgene) or a control virus under the same promoter, AAV8-CaMKII $\alpha$-EGFP (EGFP) (Addgene), was bilaterally infused at $0.1 \mu \mathrm{l} / \mathrm{min}$ to a total infusion volume of $0.25 \mu \mathrm{l}$, and the needle was left in place for $5 \mathrm{~min}$ after completion of the infusion. Upon completion of the virus infusion, the anesthesia was reversed with a subcutaneous injection of atipamezole $(0.5 \mathrm{mg} / \mathrm{kg})$.

All behavioral testing was completed 7 weeks after viral infusions to control for transgene expression (e.g., see Fig. $1 C, D$ ). The interval between viral infusion and cannulation differed between experimental procedures to maintain a consistent interval between virus infusions and testing and control for the influence of surgery on training. Cannulations for the BLA were completed 1 week before behavioral training procedures, controlling for recovery time between the final surgery and the start of behavioral training. Mice were anesthetized and mounted on a stereotaxic apparatus with the same surgical procedures as described above. Two guide cannulae (Plastics One) were surgically implanted bilaterally above the BLA $(-1.6 \mathrm{~mm} \mathrm{AP}, \pm 3.4 \mathrm{~mm} \mathrm{ML},-4.9 \mathrm{~mm}$ DV from bregma). Dummy cannulae were inserted into the guide cannulae after surgery. For viral spread analysis and drug targeting for each experiment, see Figures $1 E, F, H, 2 D, E, 3 D, E, 4 D, 5 D, E$, and $6 A, B$.

Fear conditioning. Fear conditioning was performed in four identical conditioning chambers $(7$ inch $\mathrm{W} \times 7$ inch $\mathrm{D} \times 12$ inch $\mathrm{H})$ containing two Plexiglas walls, two aluminum sidewalls, and a stainless-steel gridshock floor (Coulbourn Instruments). The training context consisted of the conditioning chamber with a polka-dot insert attached to the rear Plexiglas wall, continuous white noise $(70 \mathrm{~dB})$, dim illumination, and the stainless-steel grid floors were cleaned with $70 \%$ ethanol. The novel context consisted of the conditioning chamber with no visible illumination (illuminated only with an infrared light), fan (providing continuous presentation of $60 \mathrm{~dB}$ white noise), and flat brown Plexiglas floors, which were cleaned with 2\% Quatricide (Pharmacal Research Laboratories).

Mice were preexposed to the context twice for $5 \mathrm{~min}$ on the $2 \mathrm{~d}$ before fear conditioning. Fear conditioning occurred in the training context with five unsignaled footshocks ( $1 \mathrm{~s}, 1.0 \mathrm{~mA}$ ), each separated by $90 \mathrm{~s}$. Mice were removed from the apparatus $30 \mathrm{~s}$ after the last shock and returned to their home cage. Mice were tested for fear using a $5 \mathrm{~min}$ exposure in either the training context or the novel context at $24 \mathrm{~h}$ or $28 \mathrm{~d}$ after training.

For the clozapine-N-oxide ( $\mathrm{CNO}$ ) control experiments, mice were given $5 \mathrm{mg} / \mathrm{kg}$ intraperitoneal injections of CNO (Cayman Chemical) or saline $30 \mathrm{~min}$ before testing; these mice did not receive any virus. All mice were given $\mathrm{CNO} 30 \mathrm{~min}$ before testing in the systemic inactivation studies. Thus, the mice only varied in their transgene expression (e.g., EGFP or hM4D). The dose of $5 \mathrm{mg} / \mathrm{kg}$ was selected due to common intraperitoneal injection doses used for DREADD experiments and has shown to have reduced effects on behavior in naive mice (MacLaren et al., 2016; Jendryka et al., 2019). In experiments in which mice were given a localized infusion of $\mathrm{CNO}(0.2 \mu \mathrm{l}$ of $650 \mu \mathrm{M}$ at $0.1 \mu \mathrm{l} / \mathrm{min})$, a concentration within the range of those previously reported (Mahler et al., 2014; Vazey and Aston-Jones, 2014; Scofield et al., 2015), the drug was infused 5 min before testing to inactivate ACC or vHPC projections terminating in the 
A
TRAINING

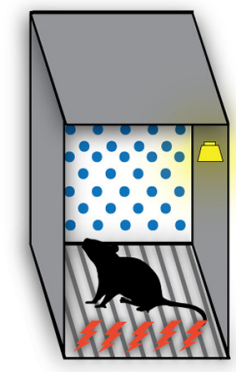

TEST

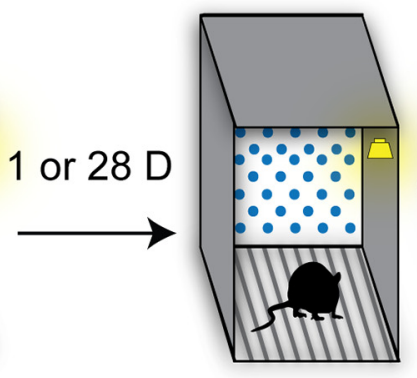

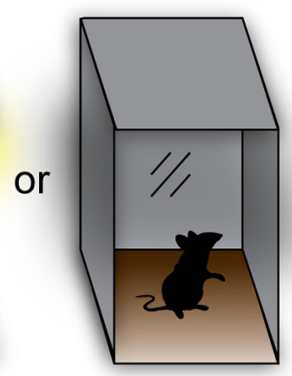

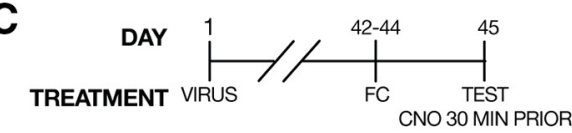

D

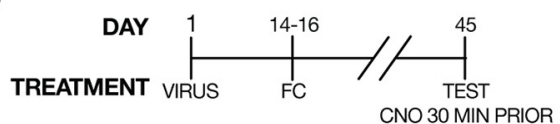

G

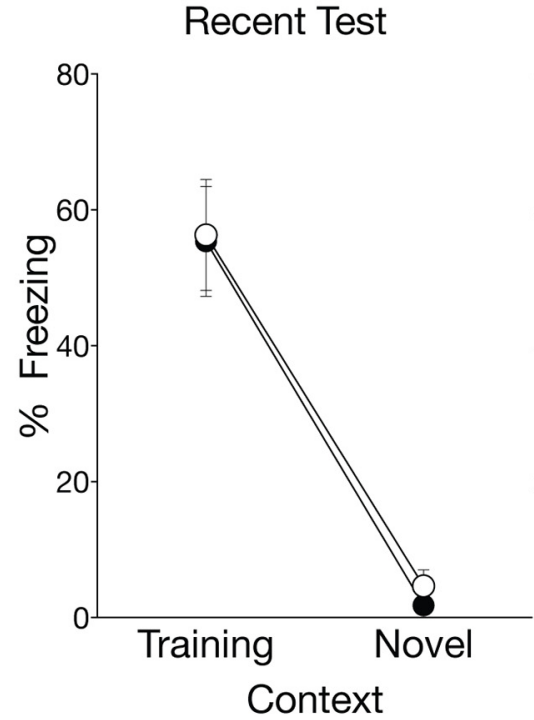

E 1.18

0.98

0.74

0.50

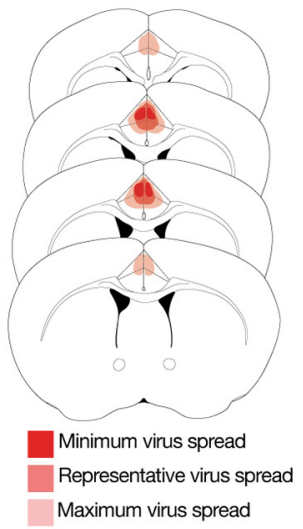

Remote Test

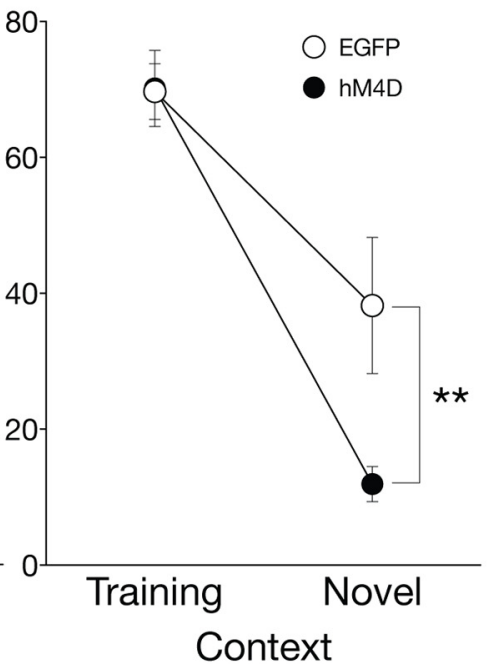

B

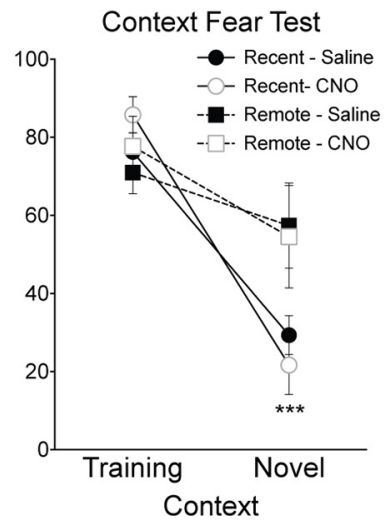

F

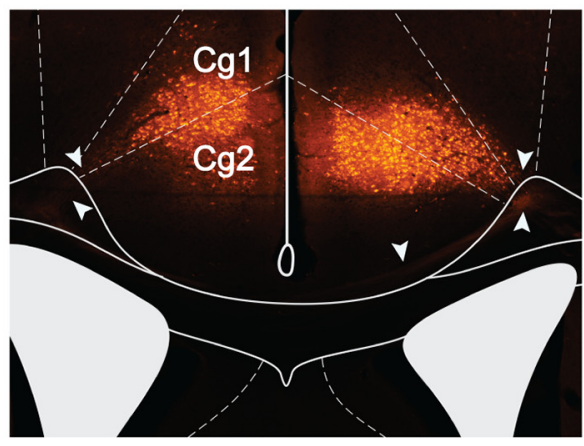

H

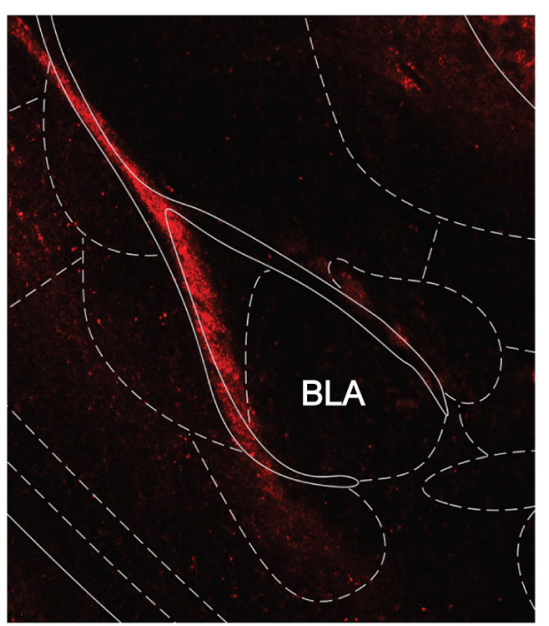

Figure 1. Inactivation of the ACC eliminates time-dependent generalized context fear. $A$, All mice underwent context fear conditioning, which consisted of five unsignaled footshocks (1 s, 1.0 $\mathrm{mA}$ ), each separated by $90 \mathrm{~s}$, in the training context, which included the conditioning chamber with a polka-dot insert attached to the rear Plexiglas wall, white noise (70 db), dim illumination, and the stainless-steel grid floors were cleaned with $70 \%$ ethanol. One day or $28 \mathrm{~d}$ after training, mice were either placed back in the training context or a distinct novel context, which included the conditioning chamber with a small exhaust fan, and flat brown Plexiglas floors, which were cleaned with 2\% Quatricide. There was no visible illumination (illuminated only with an infrared light), and no polka-dot wall insert. $\boldsymbol{B}$, There was no effect of CNO alone on context-dependent fear behavior. As a CNO control experiment, naive mice were context fear-conditioned and given an intraperitoneal injection of CNO or saline 30 min before testing either 1 or $28 \mathrm{~d}$ after training. Percent freezing levels of animals that received saline (filled symbols) or CN0 (open symbols) during recent (circles) and remote (squares) tests in the training or neutral context were analyzed ( \pm SEM). Two-way ANOVA identified a significant main effect of context at the recent time point $\left(F_{(1,12)}=\right.$ $96.40, p<0.001$ ), but not at the remote time point; mice froze significantly more in the training context than the novel context at 1 but not $28 \mathrm{~d}$ after training. ${ }^{* * *} p<0.001$, significantly different from animals tested in training context. C, On the first day of the experimental procedures, pAAV-CaMKIlla-hM4D(Gi)-mCherry virus (hM4D) or pAAV-CaMKIla-EGFP (EGFP) was bilaterally infused into the ACC. All behavioral tests were completed 7 weeks after viral infusions. For the recent test, mice were tested $1 \mathrm{~d}$ after training, $(\boldsymbol{D})$ whereas mice tested at the remote time were tested $28 \mathrm{~d}$ after training. All mice were given an intraperitoneal injection of CNO 30 min before testing. $\boldsymbol{E}$, Analysis of transgene expression in all hM4D infusions into the ACC for mice tested with systemic injection of CNO. No expression was observed outside of the ACC for systemic inactivation. Dark red represents minimum spread observed and included in analysis. Red represents typical spread observed. Light red represents maximum spread observed and included in behavioral analysis. $\boldsymbol{F}$, Representative image of pAAV-CaMKIla-hM4D(Gi)-mCherry expression in the ACC. Expression of mCherry was observed throughout the ACC and was typical of a membrane bound fluorophore. White arrows indicate fiber tracts exiting the ACC toward the corpus callosum. $\mathbf{G}$, hM4D mice administered CNO froze significantly less than EGFP control mice in the novel context only during the remote test, suggesting that inactivation of the ACC eliminates generalized fear at a remote time point. Percent freezing levels of EGFP $(O)$ and hM4D $(O)$ mice during recent (left) and remote (right) tests in the training or neutral context were analyzed ( \pm SEM). Two-way ANOVA (Figure legend continues.) 
Table 1. CNO and hybrid B6S1 behavior: statistical summary

\begin{tabular}{|c|c|c|c|c|c|c|c|c|c|c|c|c|c|}
\hline Mouse strain & Manipulation & Statistical test & $\begin{array}{l}\text { Test } \\
\text { delay }\end{array}$ & Comparison & F/t statistic & $\mathrm{df}$ & $\begin{array}{l}\% \text { total } \\
\text { variance }\end{array}$ & $p$ & * & $\eta p^{2}$ & $\begin{array}{l}\text { Effect } \\
\text { size }\end{array}$ & Power & Figure \\
\hline \multirow[t]{9}{*}{ C57BL/6 } & \multirow{6}{*}{$\begin{array}{l}\text { CNO versus } \\
\text { saline }\end{array}$} & \multirow{9}{*}{$\begin{array}{l}\text { Two-way } \\
\text { ANOVA }\end{array}$} & \multirow[t]{3}{*}{$1 d$} & Context $\times$ treatment & 2.30 & 1,12 & 2.08 & 0.155 & NS & 0.160 & 0.43 & 0.36 & \multirow[t]{9}{*}{$1 B$} \\
\hline & & & & Context & 96.40 & 1,12 & 87.10 & $<0.001$ & $* * *$ & 0.889 & 2.85 & 1.00 & \\
\hline & & & & Drug treatment & 0.03 & 1,12 & 0.02 & 0.873 & NS & 0.002 & 0.05 & 0.05 & \\
\hline & & & \multirow[t]{3}{*}{$28 d$} & Context $\times$ treatment & 0.32 & 1,11 & 2.23 & 0.584 & NS & 0.028 & 0.16 & 0.09 & \\
\hline & & & & Context & 2.61 & 1,11 & 18.7 & 0.131 & NS & 0.195 & 0.49 & 0.41 & \\
\hline & & & & Drug treatment & 0.80 & 1,11 & 0.606 & 0.774 & NS & 0.007 & 0.08 & 0.06 & \\
\hline & \multirow{3}{*}{$\begin{array}{l}\text { Three versus } \\
\text { five shock }\end{array}$} & & \multirow[t]{3}{*}{$1 d$} & Context $\times$ treatment & 5.42 & 1,19 & 4.01 & 0.03 & $*$ & 0.222 & 0.53 & 0.68 & \\
\hline & & & & Context & 90.60 & 1,19 & 67.10 & $<0.001$ & $* * *$ & 0.821 & 2.18 & 1.00 & \\
\hline & & & & Shock treatment & 16.10 & 1,19 & 11.90 & $<0.001$ & $* * *$ & 0.78 & 0.29 & 0.26 & \\
\hline
\end{tabular}

Table 2. CNO and hybrid B6S1 behavior: significant post hoc comparisons summary

\begin{tabular}{|c|c|c|c|c|c|c|c|c|c|c|c|}
\hline Statistical test & Test delay & $\begin{array}{l}\text { Significant post hoc comparisons } \\
\text { (context: treatment) }\end{array}$ & Mean 1 & Mean 2 & $N 1$ & N2 & $t$ & df & $p$ & * & Figure \\
\hline \multirow[t]{4}{*}{ Post hoc comparison } & \multirow[t]{4}{*}{$1 d$} & Training: saline versus novel: saline & 76.3 & 29.3 & 4 & 4 & 4.2 & 4 & $<0.001$ & *** & \multirow[t]{9}{*}{$1 B$} \\
\hline & & Training: saline versus novel: CNO & 76.3 & 21.7 & 4 & 4 & 4.8 & 4 & $<0.001$ & $* * *$ & \\
\hline & & Training: CNO versus novel: saline & 85.8 & 29.3 & 4 & 4 & 5 & 4 & $<0.001$ & $* * *$ & \\
\hline & & Training: CNO versus novel: CNO & 85.8 & 21.7 & 4 & 4 & 5.7 & 4 & $<0.001$ & $* * *$ & \\
\hline \multirow[t]{5}{*}{ Post hoc comparison } & \multirow[t]{5}{*}{$1 d$} & Training: 3-shock versus novel: 3-shock & 79.5 & 16.6 & 7 & 6 & 9 & 19 & $<0.001$ & $* * *$ & \\
\hline & & Training: 3-shock versus novel: 5-shock & 79.5 & 50.2 & 7 & 5 & 4 & 19 & $<0.001$ & *** & \\
\hline & & Training: 5 -shock versus novel: 3 -shock & 88.4 & 16.6 & 5 & 6 & 9.4 & 19 & $<0.001$ & $* * *$ & \\
\hline & & Training: 5-shock versus novel: 5-shock & 88.4 & 50.2 & 5 & 5 & 4.8 & 19 & $<0.001$ & *** & \\
\hline & & Novel: 3-shock versus novel: 5-shock & 16.6 & 50.2 & 6 & 5 & 4.4 & 19 & $<0.001$ & *** & \\
\hline
\end{tabular}

Table 3. ACC: statistical summary

\begin{tabular}{|c|c|c|c|c|c|c|c|c|c|c|c|c|c|}
\hline Mouse strain & Inactivation & Statistical test & $\begin{array}{l}\text { Test } \\
\text { delay }\end{array}$ & Comparison & $\begin{array}{l}F / t \\
\text { statistic }\end{array}$ & df & $\begin{array}{l}\% \text { total } \\
\text { variance }\end{array}$ & $p$ & * & $\eta p^{2}$ & $\begin{array}{l}\text { Effect } \\
\text { size }\end{array}$ & Power & Figure \\
\hline \multirow[t]{13}{*}{ (57BL/6 } & \multirow[t]{6}{*}{ Systemic } & \multirow[t]{12}{*}{ Two-way ANOVA } & \multirow[t]{3}{*}{$1 d$} & Context $\times$ treatment & 0.02 & 1,16 & 0.03 & 0.886 & - & 0.001 & 0.04 & 0.05 & \multirow[t]{6}{*}{$1 G$} \\
\hline & & & & Context & 64.20 & 1,16 & 78.80 & $<0.001$ & $* * *$ & 0.801 & 2.00 & 1.00 & \\
\hline & & & & Viral treatment & 0.08 & 1,16 & 0.10 & 0.776 & - & 0.005 & 0.07 & 0.06 & \\
\hline & & & \multirow[t]{3}{*}{$28 d$} & Context $\times$ treatment & 4.64 & 1,17 & 5.94 & 0.046 & * & 0.230 & 0.52 & 0.62 & \\
\hline & & & & Context & 52.30 & 1,17 & 66.9 & $<0.001$ & $* * *$ & 0.770 & 1.75 & 1.00 & \\
\hline & & & & Viral treatment & 4.34 & 1,17 & 5.55 & 0.053 & - & 0.219 & 0.50 & 0.59 & \\
\hline & \multirow{7}{*}{$\begin{array}{l}\text { BLA } \\
\text { terminals }\end{array}$} & & \multirow[t]{3}{*}{$1 d$} & Context $\times$ treatment & 0.32 & 1,27 & 0.42 & 0.578 & - & 0.012 & 0.10 & 0.09 & \multirow[t]{6}{*}{$2 F$} \\
\hline & & & & Context & 47.10 & 1,27 & 63.00 & $<0.001$ & $* * *$ & 0.636 & 1.32 & 0.99 & \\
\hline & & & & Viral treatment & 0.03 & 1,27 & 0.04 & 0.867 & - & 0.001 & 0.03 & 0.05 & \\
\hline & & & \multirow[t]{3}{*}{$28 d$} & Context $\times$ treatment & 6.71 & 1,35 & 10.3 & 0.014 & * & 0.161 & 0.44 & 0.76 & \\
\hline & & & & Context & 15.6 & 1,35 & 23.9 & $<0.001$ & $* * *$ & 0.308 & 0.67 & 0.98 & \\
\hline & & & & Viral treatment & 2.25 & 1,35 & 3.45 & 0.142 & - & 0.061 & 0.25 & 0.34 & \\
\hline & & $\begin{array}{l}\text { Mann-Whitney } \\
\text { Test }\end{array}$ & $28 d$ & Target location & & & & 0.019 & * & - & 8.93 & 1.00 & $2 G$ \\
\hline C57BL/6 $\times$ & & Repeated-measures & $1 d$ & Context $\times$ treatment & 5.35 & 1,10 & 5.04 & 0.043 & * & 0.333 & 0.71 & 0.97 & $3 E$ \\
\hline \multirow[t]{5}{*}{ 129S1vmJ } & & \multirow[t]{5}{*}{ two-way ANOVA } & \multirow[t]{2}{*}{$1 \mathrm{~d}$} & Context & 64.8 & 1,10 & 61 & $<0.001$ & $* * *$ & 0.858 & 2.46 & 1.00 & \\
\hline & & & & Viral treatment & 14.3 & 1,10 & 14.4 & 0.004 & $* *$ & 0.588 & 1.20 & 0.99 & \\
\hline & & & \multirow[t]{3}{*}{$28 d$} & Context $\times$ treatment & 4.93 & 1,13 & 6.28 & 0.045 & * & 0.128 & 0.39 & 0.71 & \\
\hline & & & & Context & 17.9 & 1,13 & 22.8 & $<0.001$ & $* * *$ & 0.348 & 0.73 & 0.99 & \\
\hline & & & & Viral treatment & 3.08 & 1,13 & 10.1 & 0.103 & - & 0.192 & 0.49 & 0.89 & \\
\hline
\end{tabular}

BLA. The within-subject fear testing used F1 hybrids in the same training procedures as described previously with counterbalanced testing. F1 hybrids were tested in both the training and novel contexts for $5 \mathrm{~min}$ with $72 \mathrm{~h}$ between testing. Five minutes before each test, F1 hybrids were given intra-BLA infusions of $\mathrm{CNO}$ as previously described.

(Figure legend continued.) identified a significant main effect of context at the recent time $\operatorname{point}\left(F_{(1,16)}=64.2, p<0.001\right)$ and at the remote time point $\left(F_{(1,17)}=52.3, p<0.001\right)$; mice froze more in the training context than the novel context. However, there was a significant context $\times$ treatment interaction only at the remote time point $\left(F_{(1,17)}=4.64, p<0.05\right)$. ${ }^{* *} p<0.01$. ${ }^{* *} p<0.001$. $\boldsymbol{H}$, Representative image of pAAV-CaMKIlla-hM4D(Gi)-mCherry expression in the BLA in a mouse that had virus infused into the ACC. Robust expression of $m$ Cherry was observed in the external capsule fibers entering the BLA.
Histology. Mice were deeply anesthetized with pentobarbital sodium and perfused transcardially with $0.9 \%$ saline followed by $4 \%$ PFA. After perfusion, $0.2 \mu \mathrm{l}$ of $0.5 \%$ neutral red solution was infused into the guide cannulae for site verification of BLA targets; then the brains were extracted. After extraction, brains were postfixed in 4\% PFA for $24 \mathrm{~h}$ and then transferred to $30 \%$ sucrose solution until sectioning. Coronal sections $(40 \mu \mathrm{m}$ thick, taken every $120 \mu \mathrm{m}$ ) were cut on a freezing microtome, mounted on glass microscope slide, and coverslipped with MOWIOL mounting medium containing 2.5\% DABCO before visualization. All imaging was completed on a Nikon Eclipse Ti-S using a Nikon Intensilight C-HGFIE mercury lamp in conjunction with FITC, and $\mathrm{Cy} 3$ filters and analyzed using NIS Elements software. Exclusion criteria for experiments included the following: unilateral expression of hM4D within the ACC or vHPC or no expression within the vCA1 of the 
Table 4. ACC: significant post hoc comparisons summary

\begin{tabular}{|c|c|c|c|c|c|c|c|c|c|c|c|c|c|}
\hline Mouse strain & Inactivation & Statistical test & $\begin{array}{l}\text { Test } \\
\text { delay }\end{array}$ & $\begin{array}{l}\text { Significant post hoc comparisons } \\
\text { (context: treatment) }\end{array}$ & Mean 1 & Mean 2 & N1 & N2 & $t$ & df & $p$ & * & Figure \\
\hline \multirow[t]{11}{*}{ C57BL/6 } & \multirow[t]{6}{*}{ Systemic } & Two-way & \multirow[t]{3}{*}{$1 d$} & Training: hM4D versus novel: $h M 4 D$ & 55.4 & 1.79 & 5 & 5 & 5.83 & 16 & $<0.001$ & $* * *$ & \multirow[t]{3}{*}{$1 G$} \\
\hline & & ANOVA & & Training: hM4D versus novel: EGFP & 55.4 & 4.65 & 5 & 4 & 5.2 & 16 & $<0.001$ & $* * *$ & \\
\hline & & & & Training: EGFP versus novel: EGFP & 56.3 & 4.65 & 6 & 4 & 5.51 & 16 & $<0.001$ & $* * *$ & \\
\hline & & & \multirow[t]{3}{*}{$28 d$} & Training: hM4D versus novel: hM4D & 70.1 & 11.9 & 6 & 5 & 6.78 & 17 & $<0.001$ & $* * *$ & \multirow[t]{3}{*}{$1 G$} \\
\hline & & & & Training: hM4D versus novel: EGFP & 70.1 & 38.2 & 6 & 5 & 3.72 & 17 & 0.002 & ** & \\
\hline & & & & Novel: hM4D versus novel: EGFP & 11.9 & 38.2 & 5 & 5 & 2.93 & 17 & 0.009 & ** & \\
\hline & \multirow{5}{*}{$\begin{array}{l}\text { BLA } \\
\text { terminals }\end{array}$} & & \multirow[t]{4}{*}{$1 d$} & Training: hM4D versus novel: hM4D & 41.9 & 8.26 & 7 & 8 & 4.38 & 27 & $<0.001$ & $* * *$ & \multirow[t]{5}{*}{$2 F$} \\
\hline & & & & Training: hM4D versus novel: EGFP & 41.9 & 4.34 & 7 & 8 & 4.89 & 27 & $<0.001$ & $* * *$ & \\
\hline & & & & Training: EGFP versus novel: hM4D & 44 & 8.26 & 8 & 8 & 4.82 & 27 & $<0.001$ & $* * *$ & \\
\hline & & & & Training: EGFP versus novel: EGFP & 44 & 4.34 & 8 & 8 & 5.34 & 27 & $<0.001$ & $* * *$ & \\
\hline & & & $28 d$ & Training: hM4D versus novel: hM4D & 42 & 4.13 & 10 & 13 & 5.08 & 35 & $<0.001$ & $* * *$ & \\
\hline \multirow{3}{*}{$\begin{array}{l}\text { C57BL/6 } \times \\
12951 \mathrm{vmJ}\end{array}$} & & & $1 d$ & Novel: hM4Dversus EGFP & 16.7 & 49.5 & 6 & 6 & 4.32 & 20 & $<0.001$ & $* * *$ & \multirow{3}{*}{$3 E$} \\
\hline & & & \multirow[t]{2}{*}{$28 d$} & hM4D: trainingversus novel & 67.7 & 37.6 & 8 & 8 & 4.72 & 13 & $<0.001$ & $* * *$ & \\
\hline & & & & Novel: hM4DversusEGFP & 37.6 & 61.1 & 8 & 7 & 2.66 & 26 & 0.013 & * & \\
\hline
\end{tabular}

HPC. One mouse was excluded due to hM4D cell body expression that significantly exceeded the boundaries of the ACC into the motor cortex. No expression outside of the vHPC was observed.

Statistical analyses. Mean freezing during contextual fear testing was analyzed using a $2 \times 2$ factorial ANOVA on Prism statistical software (GraphPad). Statistically significant ANOVAs were followed up with Tukey HSD post hoc comparisons. BLA target comparisons were analyzed using a nonparametric Mann-Whitney $t$ test on Prism (GraphPad). Effect sizes were calculated for completed experiments along with post hoc power analyses using $\mathrm{G}^{\star}$ Power 3 . Tables $1-6$ provide detailed statistical results for each experiment.

\section{Results \\ CNO administration alone has no effect on context fear generalization}

Before the start of neuronal manipulation with the DREADD system, we tested for nonconstitutive effects of $\mathrm{CNO}$ on fear generalization. Non-virus-infused mice were context fearconditioned and tested in the training context or a distinct novel context where they had not been previously exposed (Fig. 1A) either 1 or $28 \mathrm{~d}$ after training; $30 \mathrm{~min}$ before testing, mice were administered $\mathrm{CNO}$ or saline. $\mathrm{CNO}$ and saline controls displayed high levels of freezing to the training context and significantly lower freezing levels in the novel context at the recent time point, indicating no effect of $\mathrm{CNO}$ on normal freezing in either context (main effect of context, $F_{(1,12)}=96.4, p<0.001$; Tables 1, 2; Fig. $1 B)$. Furthermore, $\mathrm{CNO}$ had no effect on freezing at the remote test; all mice displayed high freezing levels in the training and novel context (Table 1; Fig. 1B). These data indicate that $\mathrm{CNO}$ alone, or its potential reverse metabolism to clozapine (Gomez et al., 2017), has no effect on freezing to a specific or generalized context. Thus, any effects observed on fear generalization in the following experiments are due to hM4D receptor inactivation in the targeted region.

\section{The ACC, BLA circuit controls time-independent generalized fear}

Our initial finding that the ACC plays a critical role in the generalization of context fear (Cullen et al., 2015) was upheld using hM4D inactivation. hM4D-mediated inactivation of the ACC with a systemic injection of CNO eliminated generalized fear to the novel context, but not specific fear to the training context (remote context $\times$ treatment interaction, $F_{(1,17)}=4.64, p<$ 0.001; Tables 3, 4; Fig. 1G). Therefore, we used the hM4D system with intracranial infusions of $\mathrm{CNO}$ to identify the precise ACC circuit that regulates fear generalization. The ACC is known to convey sensory information to the BLA (Morozov et al., 2011; McCullough et al., 2016); therefore, we targeted ACC projection terminals in the BLA.

Mice with hM4D or EGFP virus in the ACC were context fear-conditioned; 5 min before testing, all mice were administered intracranial infusions of $\mathrm{CNO}$ via guide cannulae into the BLA (Fig. $2 A-C$ ). Inactivation of the hM4D-expressing terminals from the ACC in the BLA did not affect freezing in the training or novel context during the recent test; both hM4D and EGFP groups displayed high freezing in the training context and low freezing in the novel context (main effect of context, $F_{(1,27)}=$ 47.10, $p<0.001$; Tables 3, 4; Fig. 2F, left). However, inactivating ACC terminals in the BLA significantly reduced freezing only in the novel context $28 \mathrm{~d}$ after training (context $\times$ treatment interaction, $F_{(1,35)}=6.71, p=0.014$; Tables 3, 4; Fig. 2F, right), whereas EGFP mice displayed equivalent freezing in the training and novel contexts, indicating generalized fear. The reduction of fear generalization in hM4D mice was specific to terminal inactivation within the BLA; hM4D mice with extra-BLA infusions froze significantly more in the novel context than those with intra-BLA infusions while using a Mann-Whitney nonparametric $t$ test ( $p=0.019$; Table 3; Fig. $2 G$ ). Thus, we established that projections from the ACC to the BLA are critical for promoting generalized fear at remote testing points.

Are the ACC projections to the BLA that support generalized fear restricted solely to remote tests? If generalization occurs rapidly, does the ACC-BLA circuit still control generalization? Based on our previous findings (Cullen et al., 2015) and the experiments above, we predicted that ACC projections to the BLA would only support generalized fear that develops over time. In Experiment 3, we used the F1 hybrids of C57BL/6J crossed with 

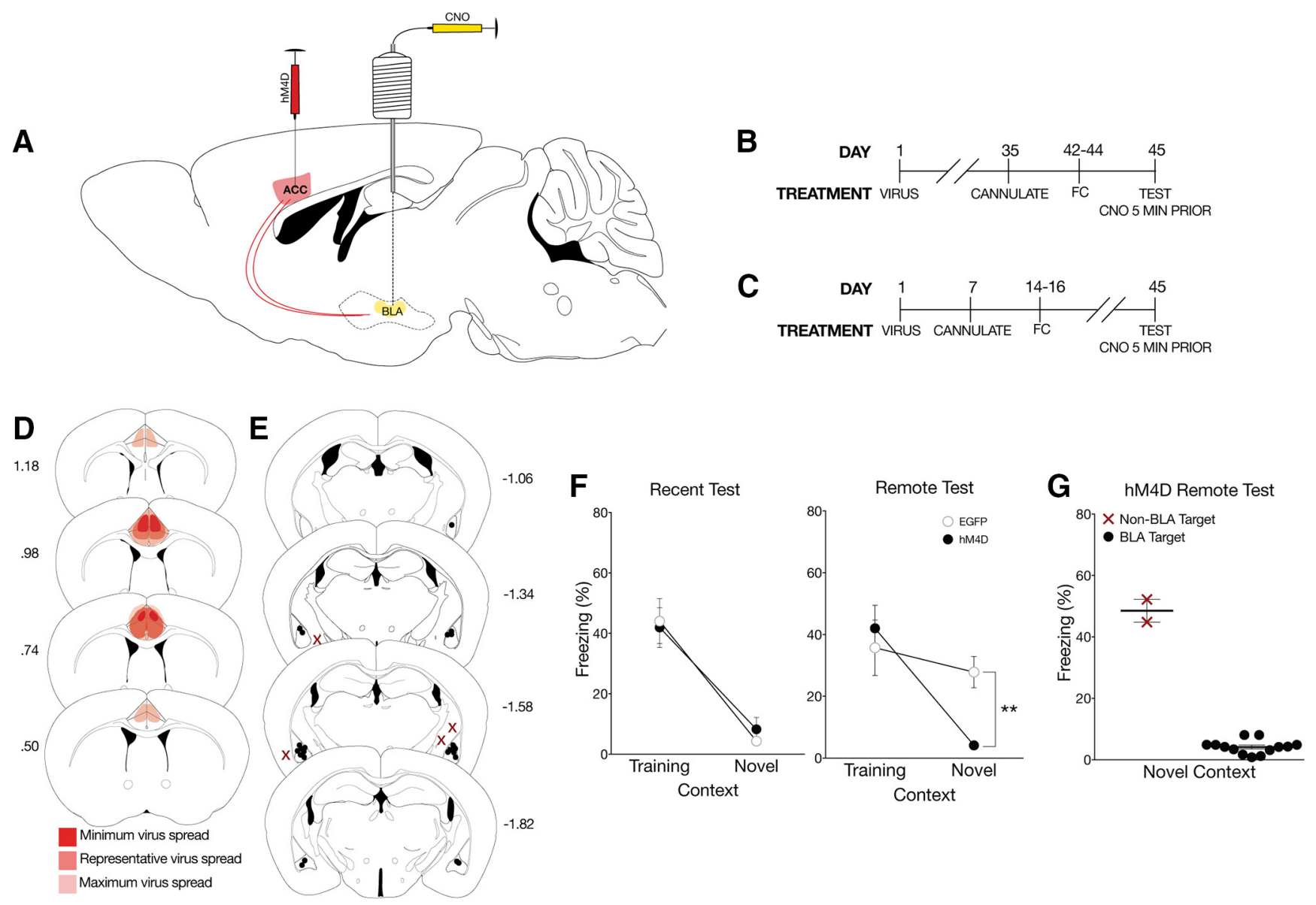

Figure 2. Inactivation of ACC CaMKII $\alpha$ projections in the BLA eliminates time-dependent generalized fear. $\boldsymbol{A}$, To identify whether the ACC regulates fear generalization via CaMKII $\alpha$ projections to the BLA, pAAV-CaMKIla-hM4D(Gi)-mCherry virus (hM4D) or pAAV-CaMKIla-EGFP (EGFP) was bilaterally infused into the ACC followed by cannulations targeting their axon terminals in the BLA. B, All behavioral tests were completed 7 weeks after viral infusions. Cannulations for the BLA were completed 1 week before behavioral training procedures. Mice were tested $1 \mathrm{~d}$ or $(\boldsymbol{C}) 28 \mathrm{~d}$ after training. All mice were given a local infusion of CNO into the BLA 5 min before testing to inactivate ACC CaMKII $\alpha$ projections. D, Analysis of transgene expression in all hM4D mice tested with inactivation of BLA terminals. One mouse was excluded from analysis due to significant hM4D expression in the motor cortex. Dark red represents minimum spread observed and included in analysis. Red represents typical spread observed. Light red represents maximum spread observed and included in behavioral analysis. $\boldsymbol{E}$, Cannulation targets within the BLA. Black dots indicate animals included in behavioral analyses. Red Xs indicate missed targets and used in a site-specific control analysis. $F$, hM4D mice with inactivated CaMKII $\alpha$ projections from the ACC to the BLA froze significantly less than EGFP mice in the novel context, but not in the training context only at the remote test. Percent freezing levels of EGFP $(O)$ and hM4D $(-$ ) mice during recent (left) and remote (right) tests in the training or neutral context 5 min after a microinfusion of CNO were analyzed ( \pm SEM). A two-way ANOVA identified a significant effect of context at the recent test $\left(F_{(1,27)}=47.1, p<0.001\right)$ and remote test $\left(F_{(1,35)}=15.6, p<0.001\right)$. As observed previously, there was a significant interaction only at the remote test $\left(F_{(1,35)}=6.71, p<0.05\right)$. Thus, inactivation of ACC CaMKII $\alpha$ projections to the BLA eliminated time-dependent generalized fear. G, $\mathrm{hM} 4 \mathrm{D}$ mice with extra-BLA infusions did not show a reduction in freezing in the novel context. Percent freezing levels of hM4D mice tested in the neutral context with missed BLA targeting compared with hM4D mice with specific targeting in the BLA was analyzed ( \pm SEM). A nonparametric Mann-Whitney $t$ test showed a significant effect of CNO infusion target $(p<0.05)$. ${ }^{* *} p<0.01$.

129S1/SvImJ, a hybrid mouse line used by several laboratories to study mechanisms of contextual fear (Frankland et al., 2004b; Smith et al., 2007; Wiltgen and Silva, 2007; Wiltgen et al., 2010; Tanaka et al., 2014) due to their rapid learning and high reliability in fear learning. This gave us the advantage of ensuring that our experimental results were not restricted to C57BL/6J mice, as there is considerable variability in learning and behavior across mouse lines (Hefner et al., 2008). We first performed behavioral parametrics with the F1 hybrid line and found a significant effect of number of shocks on the timing of generalization (context $\times$ shock interaction, $F_{(1,19)}=5.42$, $p=0.03$; Table 1; Fig. $3 A$ ). Hybrid mice displayed high levels of freezing in the novel context $1 \mathrm{~d}$ after training if the mice received 5 footshocks, yet this was not observed if the mice received only 3 footshocks (Table 1; Fig. $3 A$ ), thus providing a novel opportunity to study the role of the ACC-BLA-vHPC circuit in nontemporally graded generalization.
Experimental procedures were performed as described in Experiment 2; however, mice were tested a second time $72 \mathrm{~h}$ after the first test in the opposite context to reduce potential testingorder effects and allow for CNO to be completely metabolized before the second test (Fig. $3 B, C$ ). Hybrid mice with EGFP virus displayed increased freezing in the novel context during recent and remote tests (Fig. 3F, left). Unexpectedly, hM4D inactivation of the projections from the ACC to the BLA at both the recent (context $\times$ treatment interaction, $F_{(1,10)}=5.35, p=0.043$ ) and remote (context $\times$ treatment interaction, $F_{(1,13)}=4.93, p=$ 0.045 ) tests reduced freezing in the novel context but not in the training context (Tables 3, 4; Fig. 3F), indicating that projections from the ACC to the BLA promote freezing to a novel context in a time-independent manner. The ACC-BLA pathway controls generalized fear to the novel context but not specific fear to the training context; this effect is upheld across mouse strains and experimental testing designs. 
A

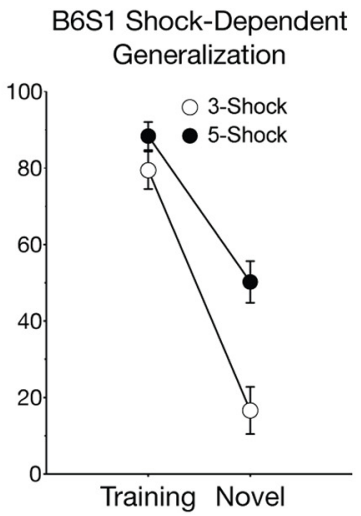

B

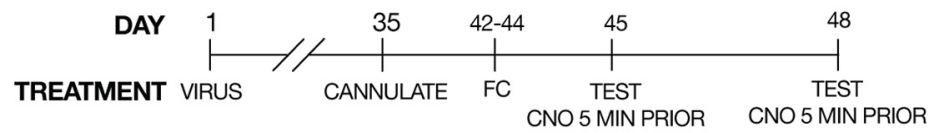

C

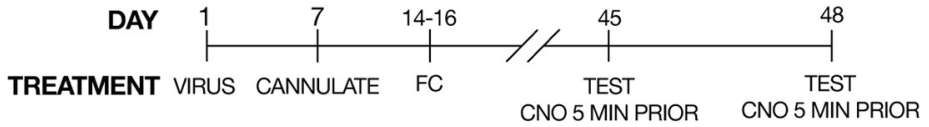

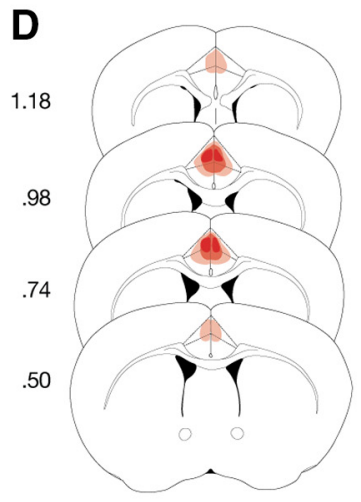

Minimum virus spread Representative virus spread Maximum virus spread
E

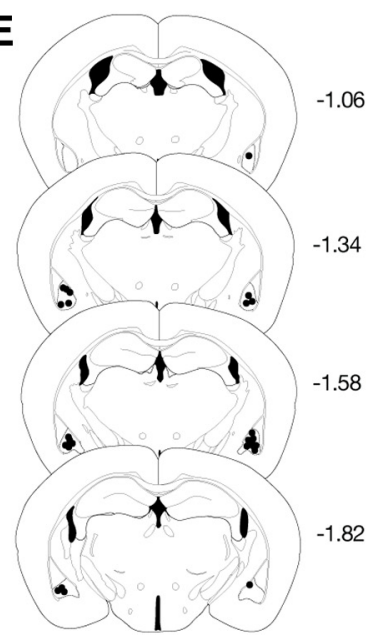

$\mathbf{F}$

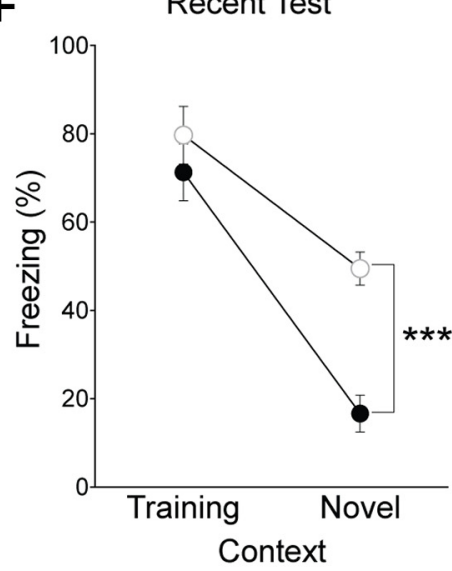

Remote Test

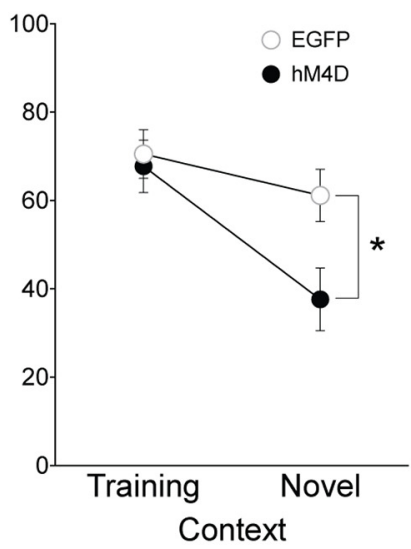

Figure 3. Inactivation of ACC to BLA CaMKIl $\alpha$ projections eliminates time-independent generalized fear. A, Hybrid B6S1 mice were tested for contextual fear after training with either $3,1 \mathrm{~mA}$ shocks or $5,1 \mathrm{~mA}$ shocks. Percent freezing levels of 3 shock $(O)$ and 5 shock $(O)$ trained mice in the training context were analyzed ( \pm SEM). A two-way ANOVA identified significant shock $X$ context interaction $\left(F_{(1,19)}=5.42, p<0.05\right)$, showing that 5-shock training, but not 3-shock training, significantly increased freezing in the novel context at the $24 \mathrm{~h}$ test. $\boldsymbol{B}$, All behavioral tests were completed 7 weeks after viral infusions. Cannulations for the BLA were completed 1 week before behavioral training procedures. In this experiment, rapid generalization was induced using a hybrid mouse line. Mice were tested once in each context at $1 \mathrm{~d}$ or $(C) 28 \mathrm{~d}$ after training with a $72 \mathrm{~h}$ intertest interval. All mice were given a local infusion of CNO into the BLA 5 min before testing to inactivate ACC CaMKII $\alpha$ projections. D, As done previously, mice were infused with the hM4D or EGFP virus into the ACC with cannulations targeting the BLA. Viral spread analysis of all hM4D mice tested using a within-subject design with inactivation of BLA terminals identified no expression outside of the ACC. Dark red represents minimum spread observed and included in analysis. Red represents typical spread observed. Light red represents maximum spread observed and included in behavioral analysis. E, Cannulation targets were analyzed to correct placement into the BLA. No mice had targets localized outside of the BLA in this experiment. $\boldsymbol{F}$, At recent and remote tests, inactivating CaMKII $\alpha$ projections from the ACC to the BLA significantly reduced freezing to the novel context. Percent freezing levels of EGFP $(\bigcirc)$ and hM4D $(\bigcirc)$ mice during within-subject recent (left) or remote (right) tests in the training and neutral context 5 min after a microinfusion of CNO were analyzed ( $( \pm$ SEM). A two-way ANOVA identified significant main effects of context at the recent $\left(F_{(1,10)}=64.8, p<0.001\right)$ and remote tests $\left(F_{(1,13)}=17.9, p<0.001\right)$. However, for the first time, there was a significant interaction at the recent $\left(F_{(1,10)}=5.35, p<0.05\right)$ and remote times $\left(F_{(1,13)}=4.93, p<0.05\right)$, suggesting that ACC CaMKIl $\alpha$ projections to the BLA control a time-independent form of generalization. ${ }^{*} p<0.01,{ }^{* * *} p<0.001$.

\section{The vHPC, BLA circuit coordinates time-dependent generalized fear}

In addition to identifying the ACC as a critical locus supporting generalized contextual fear, we previously identified that the vCA1 of the HPC also underlies generalized contextual fear at remote time points (Cullen et al., 2015). This finding was replicated by using hM4D to inactivate the vHPC. Inactivation of the vHPC with a systemic injection of CNO significantly reduced generalized fear to the novel context but not specific fear to the training context at a remote time point (remote context $\times$ treatment interaction, $F_{(1,16)}=15.90, p<0.001$; Tables 5, 6; Fig. 4C). As done with Experiment 2, we used intracranial infusions of CNO to identify the vHPC circuit that regulates fear generalization. Given that the vCA1 of the HPC has direct connections with the BLA (Cenquizca and Swanson, 2007; Fanselow and Dong, 2010) and is thought to be crucial for conveying contextual information to the BLA
(Maren and Fanselow, 1995; Huff et al., 2016), we targeted vHPC projections terminating in this region.

Mice with hM4D virus or EGFP control virus in the vHPC were context fear-conditioned; $5 \mathrm{~min}$ before testing, all mice were given intracranial infusions of $\mathrm{CNO}$ via guide cannulae into the BLA (Fig. $5 A-C$ ). Inactivation of hM4D terminals from the vHPC in the BLA did not affect freezing in the training or novel context during the recent test; both hM4D and EGFP groups displayed high freezing in the training context and low freezing in the novel context (main effect of context, $F_{(1,20)}=68.6, p<$ 0.001; Tables 5, 6; Fig. 5F, left). When mice were tested $28 \mathrm{~d}$ after training, EGFP-expressing mice displayed equivalent freezing levels in the training and novel contexts (context $\times$ treatment interaction, $F_{(1,24)}=4.34, p=0.048$; Tables 5, 6; Fig. 5F, right), indicating generalized fear. hM4D inactivation of the vHPC terminals in the BLA significantly reduced freezing in the novel context but did not alter freezing in the training context. Again, 
Table 5. Ventral hippocampus cortex: statistical analysis summary

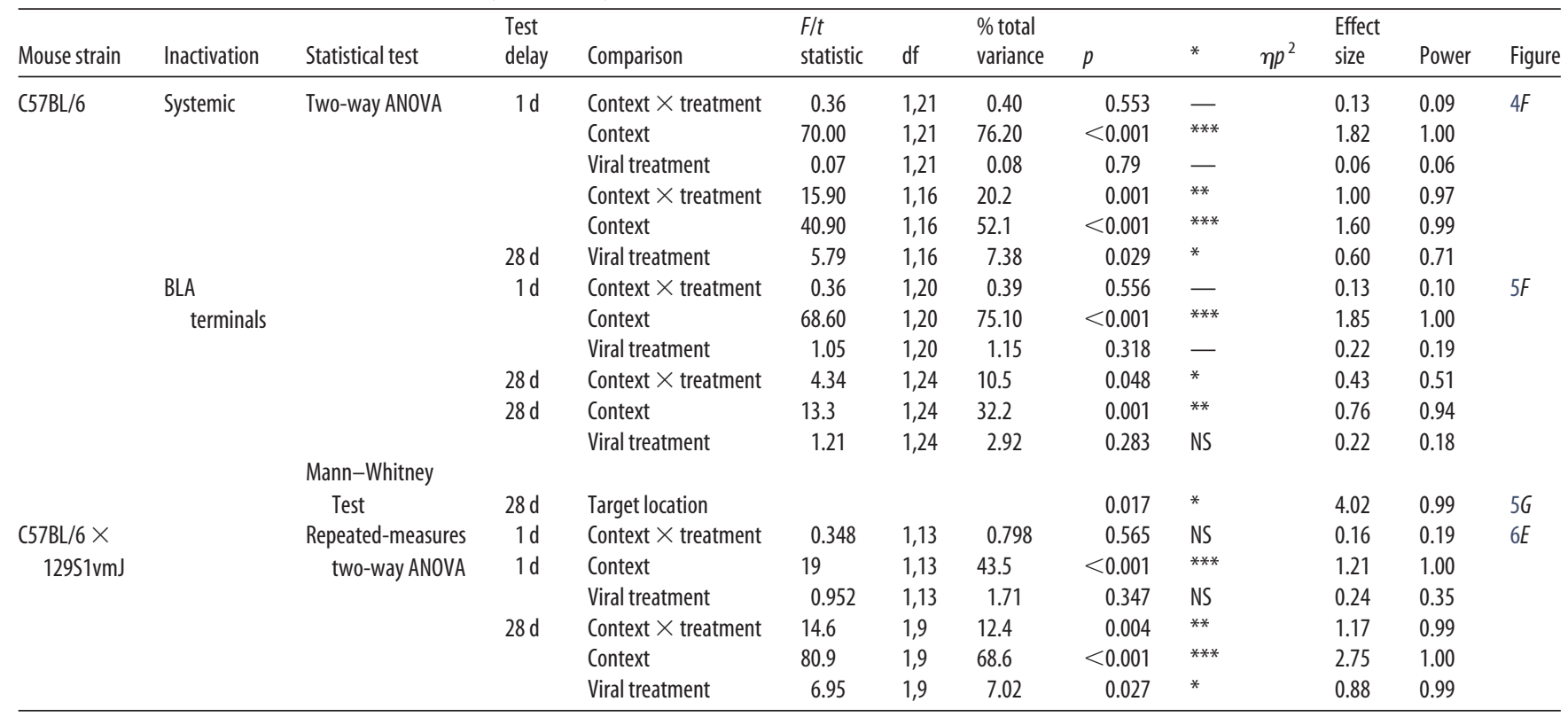

Table 6. Ventral hippocampus: significant post hoc comparisons summary

\begin{tabular}{|c|c|c|c|c|c|c|c|c|c|c|c|c|c|}
\hline Mouse strain & Inactivation & Statistical test & $\begin{array}{l}\text { Test } \\
\text { delay }\end{array}$ & $\begin{array}{l}\text { Significant post hoc comparisons } \\
\text { (context: treatment) }\end{array}$ & Mean 1 & Mean 2 & $N 1$ & N2 & $t$ & df & $p$ & * & Figure \\
\hline \multirow[t]{15}{*}{ C57BL/6 } & \multirow[t]{8}{*}{ Systemic } & Two-way & \multirow[t]{4}{*}{$1 \mathrm{~d}$} & Training: hM4D versus novel: hM4D & 58.9 & 5.36 & 6 & 7 & 6.5 & 21 & $<0.001$ & $* * *$ & \multirow[t]{8}{*}{$4 F$} \\
\hline & & ANOVA & & Training: hM4D versus novel: EGFP & 58.9 & 7.35 & 6 & 6 & 6 & 21 & $<0.001$ & $* * *$ & \\
\hline & & & & Training: EGFP versus novel: hM4D & 53.7 & 5.36 & 6 & 7 & 5.8 & 21 & $<0.001$ & $* * *$ & \\
\hline & & & & Training: EGFP versus novel: EGFP & 53.7 & 7.35 & 6 & 6 & 5.4 & 21 & $<0.001$ & $* * *$ & \\
\hline & & & \multirow[t]{4}{*}{$28 d$} & Training: hM4D versus novel: hM4D & 70.2 & 7.1 & 5 & 5 & 7.3 & 16 & $<0.001$ & $* * *$ & \\
\hline & & & & Training: hM4D versus novel: EGFP & 70.2 & 46 & 5 & 5 & 2.8 & 16 & 0.012 & * & \\
\hline & & & & Training: EGFP versus novel: hM4D & 60.7 & 7.1 & 5 & 5 & 6.2 & 16 & $<0.001$ & $* * *$ & \\
\hline & & & & Novel: hM4D versus novel: EGFP & 7.1 & 46 & 5 & 5 & 4.5 & 16 & $<0.001$ & $* * *$ & \\
\hline & \multirow{7}{*}{\multicolumn{2}{|c|}{$\begin{array}{l}\text { BLA } \\
\text { terminals }\end{array}$}} & \multirow[t]{4}{*}{$1 \mathrm{~d}$} & Training: hM4D versus novel: hM4D & 51.6 & 4.57 & 6 & 5 & 5.2 & 20 & $<0.001$ & $* * *$ & \multirow[t]{7}{*}{$5 F$} \\
\hline & & & & Training: hM4D versus novel: EGFP & 51.6 & 7.16 & 6 & 6 & 5.2 & 20 & $<0.001$ & $* * *$ & \\
\hline & & & & Training: EGFP versus novel: hM4D & 61.6 & 4.57 & 7 & 5 & 6.5 & 20 & $<0.001$ & *** & \\
\hline & & & & Training: EGFP versus novel: EGFP & 61.6 & 7.16 & 7 & 6 & 6.6 & 20 & $<0.001$ & $* * *$ & \\
\hline & & & \multirow[t]{3}{*}{$28 \mathrm{~d}$} & Training: hM4D versus novel: hM4D & 58.7 & 7.9 & 7 & 6 & 3.9 & 24 & $<0.001$ & $* * *$ & \\
\hline & & & & Training: EGFP versus novel: hM4D & 50 & 7.9 & 7 & 6 & 3.2 & 24 & 0.003 & ** & \\
\hline & & & & Novel: hM4D versus novel: EGFP & 7.9 & 36.1 & 6 & 8 & 2.2 & 24 & 0.035 & * & \\
\hline \multirow{5}{*}{$\begin{array}{l}\text { C57BL/6 } \times \\
12951 v m J\end{array}$} & & Repeated-measures & $1 d$ & hM4D: training versus novel & 62.8 & 40.6 & 7 & 7 & 2.6 & 13 & 0.023 & * & \multirow[t]{5}{*}{$6 E$} \\
\hline & & two-way ANOVA & & EGFP: training versus novel & 71.3 & 42.2 & 8 & 8 & 3.6 & 13 & 0.003 & ** & \\
\hline & & & \multirow[t]{3}{*}{$28 d$} & hM4D: training versus novel & 80.8 & 14.5 & 5 & 5 & 8.7 & 9 & $<0.001$ & $* * *$ & \\
\hline & & & & EGFP: training versus novel & 76 & 49.2 & 6 & 6 & 3.8 & 9 & 0.008 & $* *$ & \\
\hline & & & & Novel: hM4D versus novel: EGFP & 14.5 & 49.2 & 5 & 6 & 4.5 & 18 & $<0.001$ & $* * *$ & \\
\hline
\end{tabular}

this effect observed in hM4D-expressing mice was specific to projections from the vHPC terminating in the BLA. HM4D mice with targets outside of the BLA froze significantly more in the novel context at a remote time point than those with correct target placement within the BLA, even though they both expressed hM4D and received intracranial CNO infusions while using a Mann-Whitney nonparametric $t$ test $(~ p=0.017$; Table 5; Fig. $5 G$ ). These findings indicate that activity of vHPC projections, likely via vCA1 outputs (Cenquizca and Swanson, 2007; Cullen et al., 2015), to the BLA promote generalized fear, but only at a remote time point.

Are the vHPC projections to the BLA that support generalized fear restricted to remote tests? As with Experiment 3, during the recent test, EGFP F1 hybrids displayed increased freezing in the novel context (Tables 5, 6; Fig. 6E, left), dis- playing recent fear generalization. However, unlike the results from ACC-BLA circuit, inactivation of vHPC terminals in the BLA at the recent time point did not reduce freezing in the novel context or the training context; reduced generalization was only observed at the remote time point (remote context $X$ treatment interaction, $F_{(1,9)}=14.6, p=0.004$; Tables 5, 6; Fig. $6 E$ ). Given that our previous tests in the novel context at the recent time point had a floor effect, these experiments identified, for the first time, a strictly time-dependent role of the vHPC-BLA circuit in supporting generalized contextual fear. Conversely, the ACC governs generalization at both recent and remote tests. Thus, our evidence supports a role for the ACC in supporting generalized fear regardless of the passage of time, whereas the vHPC is engaged in support of generalized fear only at a remote time point. 
A

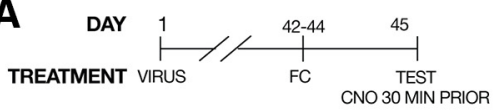

B
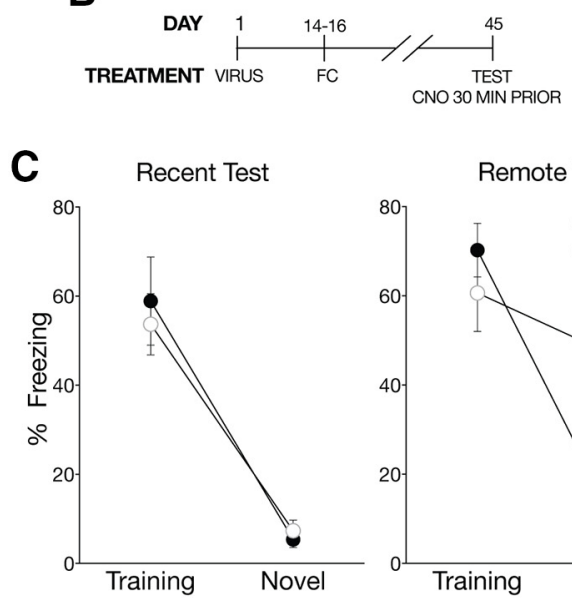
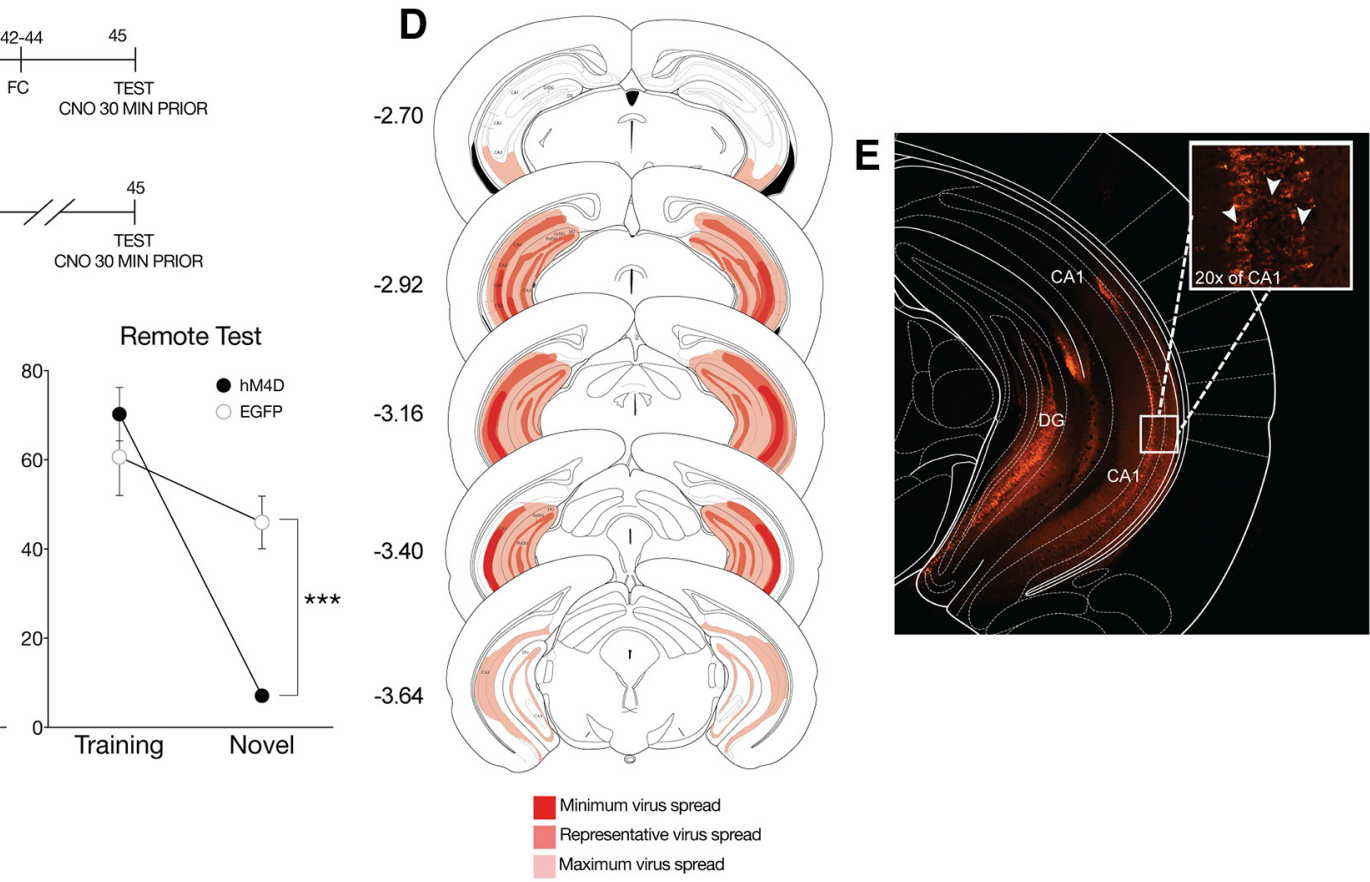

Figure 4. Inactivation of the vHPC eliminates time-dependent context fear generalization. $\boldsymbol{A}, 0 \mathrm{n}$ the first day of the experimental procedures, pAAV-CaMKIla-hM4D(Gi)-mCherry virus (hM4D) or pAAV-CaMKIla-EGFP (EGFP) was bilaterally infused into the vHPC. All behavioral tests were completed 7 weeks after viral infusions. For the recent test, mice were tested $1 \mathrm{~d}$ after training, $(\boldsymbol{B})$ whereas mice tested at the remote time were tested $28 \mathrm{~d}$ after training. All mice were given an intraperitoneal injection of $\mathrm{CN} 030 \mathrm{~min}$ before testing. $\boldsymbol{C}$, hM4D mice administered CNO froze significantly less than EGFP control mice in the novel context only. Percent freezing levels of EGFP $(O)$ and $h M 4 D(O)$ mice during recent (left panel) and remote (right panel) tests in the training or neutral context were analyzed ( \pm SEM). Two-way ANOVA identified a significant main effect of context at the recent time point, $F_{(1,21)}=70, p<$ 0.001 , and at the remote time point $F_{(1,16)}=40.9, p<0.001$; mice froze more in the training context than the novel context. However, there was a significant context $\times$ treatment interaction only at the remote time point $F_{(1,16)}=15.9, p<0.01$. ${ }^{* * *} p<0.001$, suggesting that the vHPC also regulates time-dependent generalized fear. $\boldsymbol{D}$, Analysis of transgene expression in hM4D infusions into the vHPC for mice tested with systemic injection of CNO. No expression was observed outside of the vHPC. Dark red: minimum spread observed and included in analysis; red: represents typical spread observed; light red: maximum spread observed and included in behavioral analysis. $\boldsymbol{E}$, Representative photomicrograph of pAAVCaMKIla-hM4D(Gi)-mCherry expression in the vHPC. Robust transgene expression was observed throughout the vHPC and typical of a membrane-bound fluorophore. Inset, $20 \times$ magnification. White arrows indicate examples of somatic transgene expression.

\section{Discussion}

Clinical studies implicate that the hyperreactive amygdalae observed in people with anxiety disorders may be due to an inhibitory dysregulation caused by a malfunctioning ACC and HPC (Gurvits et al., 1996; Yamasue et al., 2003; Shin et al., 2006; Woodward et al., 2006; Asami et al., 2008; Chen and Etkin, 2013; Greenberg et al., 2013). These studies are limited in making causal conclusions about connectivity, as they associate hyperactive amygdalae with decreased volume and activity of the ACC or HPC. Here, we identified causal relationships that fear to novel contexts is indeed regulated by the glutamatergic, CaMKII $\alpha$ expressing projection neurons from the ACC and vHPC to the BLA but via separate training- and time-dependent mechanisms. The regulation of generalized fear by projections from the ACC to the BLA is a time-independent effect that may depend on the strength of the training based on our finding that 5-shock, not 3 -shock, training induced generalization within $24 \mathrm{~h}$. These findings support recent hypotheses that propose that the ACC regulates generalized fear responses (Teyler and Rudy, 2007; Winocur et al., 2007; Einarsson and Nader, 2012; Cullen et al., 2015), but not specific fear responses. The time-independent mechanism of the ACC-BLA connection is in contrast to what we observed with the vHPC. When we induced rapid generalization, inactivation of projections from the vHPC to the BLA did not reduce freezing in the novel context. Generalization was only eliminated when the vHPC-BLA circuit was inactivated at a remote time point. Thus, the vHPC-BLA circuit plays a specific role in time-dependent generalization of contextual fear. Inactivation of either region or their projections to the BLA did not alter freezing in the training context. These null findings could not be due to masked effects from high levels of freezing, as freezing levels to the training context varied among experiments. However, it may be possible that the lack of effect observed in the training context is due to the unique aspects of each specific context because we did not counterbalance training between contexts. We think this explanation is unlikely because each context had corresponding, yet shifted, auditory, visual, and olfactory cues.

We have consistently observed a role for the ACC that is specific to generalized fear responding (Cullen et al., 2015), and this is supported by other recent work (Einarsson et al., 2015). We note two prior studies, which found that the ACC regulates specific fear responses at remote time points after training (Frankland et al., 2004a; Goshen et al., 2011). In one case, this discrepancy could be due to specific methodological differences during testing; we performed local intracranial infusions of $\mathrm{CNO}$ without anesthetizing mice before testing, unlike the previous study (Frankland et al., 2004a). In the other case, the authors performed tone-dependent fear training with context as background and used multiple recall tests in the same context (Goshen et al., 2011). Here, we used unsignaled shocks to train specifically for contextual fear, and mice were only tested in a single context once. This discrepancy provides evidence that ACC regulation of fear responses is related to the strength, and type, of 

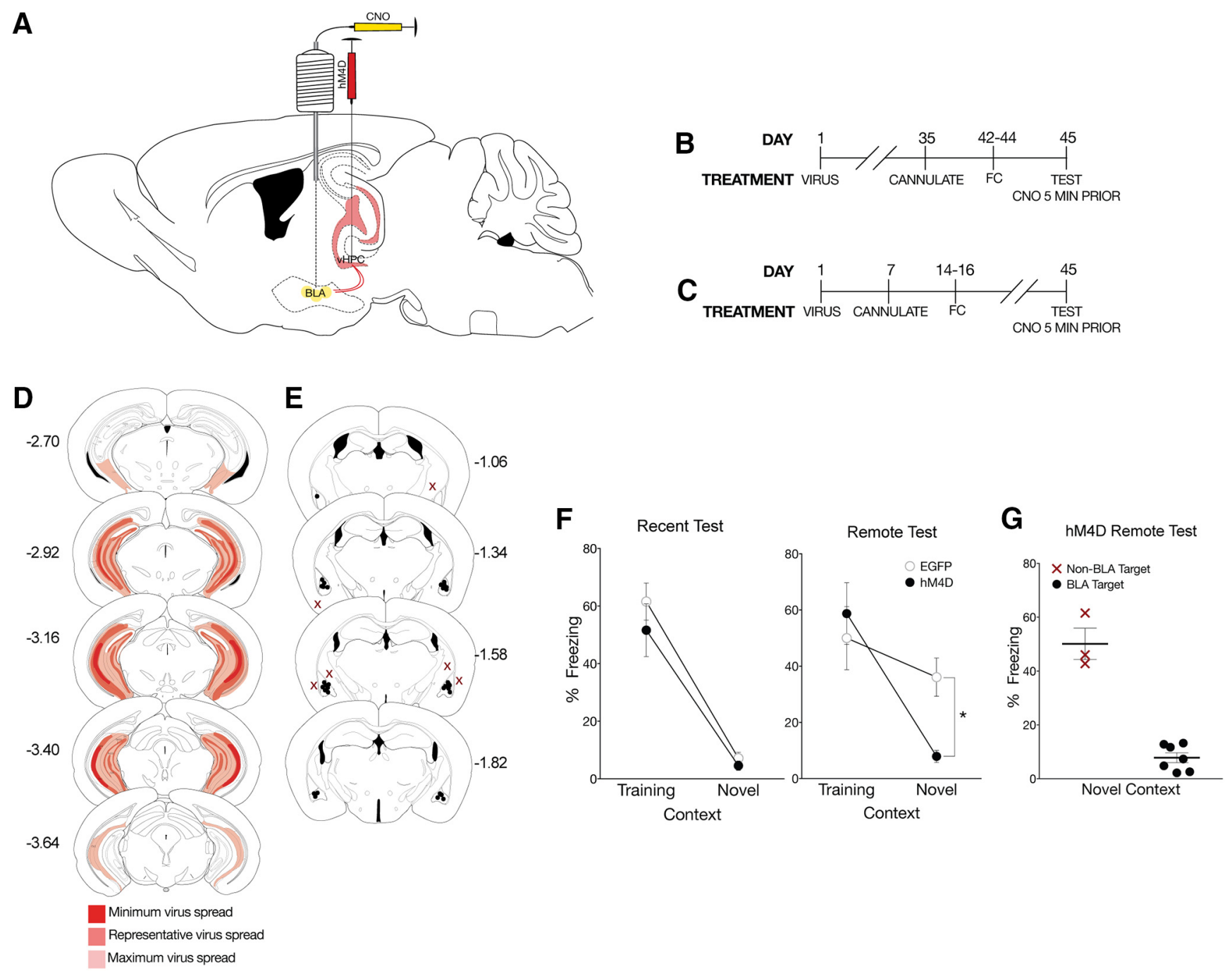

Figure 5. CaMKII $\alpha$ projections from the vHPC to the BLA regulate time-dependent generalization. $A$, To identify whether the vHPC regulates fear generalization via its CaMKII $\alpha$ projections to the BLA, pAAV-CaMKIla-hM4D(Gi)-mCherry virus (hM4D) or pAAV-CaMKIla-EGFP (EGFP) was bilaterally infused into the vHPC followed by cannulations targeting the BLA. $B$, All behavioral tests were completed 7 weeks after viral infusions. Cannulations for the BLA were completed 1 week before behavioral training procedures. Mice were tested $1 \mathrm{~d}$ or $(\boldsymbol{C})$ $28 \mathrm{~d}$ after training. All mice were given a local infusion of CNO into the BLA 5 min before testing. $\boldsymbol{D}$, Viral spread analysis of all hM4D mice tested with inactivation of BLA terminals. Dark red represents typical minimum spread observed and included in analysis. Red represents spread observed. Light red represents maximum spread observed and included in behavioral analysis. $\boldsymbol{E}$, Cannulation targets within the BLA. Black dots indicate animals included in behavioral analyses. Red Xs indicate missed targets and used in a site-specific control analysis. $\boldsymbol{F}$, hM4D mice with inactivated CaMKII $\alpha$ projections from the VHPC to the BLA froze significantly less than EGFP mice in the novel context, but not in the training context. Percent freezing levels of EGFP $(O)$ and hM4D $(\bigcirc)$ mice during recent (left) and remote (right) tests in the training or neutral context 5 min after a microinfusion of CNO were analyzed ( \pm SEM). A two-way ANOVA identified a significant effect of context at the recent test $\left(F_{(1,20)}=68.6, p<0.001\right)$ and remote test $\left(F_{(1,24)}=13.3 p<0.01\right)$. As observed previously, there was a significant interaction only at the remote test $\left(F_{(1,24)}=4.34, p<0.05\right) . G, \mathrm{hM} 4 \mathrm{D}$ mice with off-target infusions did not show a reduction in freezing in the novel context. Percent freezing levels of hM4D mice tested in the neutral context with missed BLA targeting compared with hM4D mice with specific targeting in the BLA was analyzed ( \pm SEM). A nonparametric Mann-Whitney $t$ test showed a significant effect of CNO infusion target $(p<0.05)$. ${ }^{*} p<0.05$.

the fear training. This was not the case for the role of the vHPC in generalized fear responding.

Currently, we do not fully understand the mechanisms underlying the requirement of both the ACC and $\mathrm{vHPC}$, at a remote time point, to promote generalization; inactivation of either region had the same effect of reducing generalization. The implications of these results suggest a time-dependent reorganization of local circuits and/or projections to the BLA that make recruitment of the vHPC required only at a remote time point. However, it is not clear whether the BLA recruits the vHPC or the vHPC becomes inherently involved as a function of time.

Our study is not the first to demonstrate circuits involved in generalization. Previously, Xu and Südhof (2013) proposed that the convergence of the ACC and vHPC in the nucleus reunions was a "closed" circuit which encodes context-specific fear, as they were able to induce generalization by inactivating this circuit (Xu and Südhof, 2013). Little has been done investigating how these regions act to promote fear responses after the initial training has consolidated successfully. Here, we identify circuits governing generalization at the retrieval phase and provide support for additional regions, such as the BLA, being involved in the processing of generalized fear. Additionally, in the Xu and Südhof (2013) study, transgene expression encompassed much of the dorsal medial prefrontal cortex (dmPFC), including the infralimbic and prelimbic cortices, leaving the identity of the exact subregion contributing to generalization unknown.

Few studies have investigated the neural circuit of the timedependent nature of generalization, which was the primary aim 

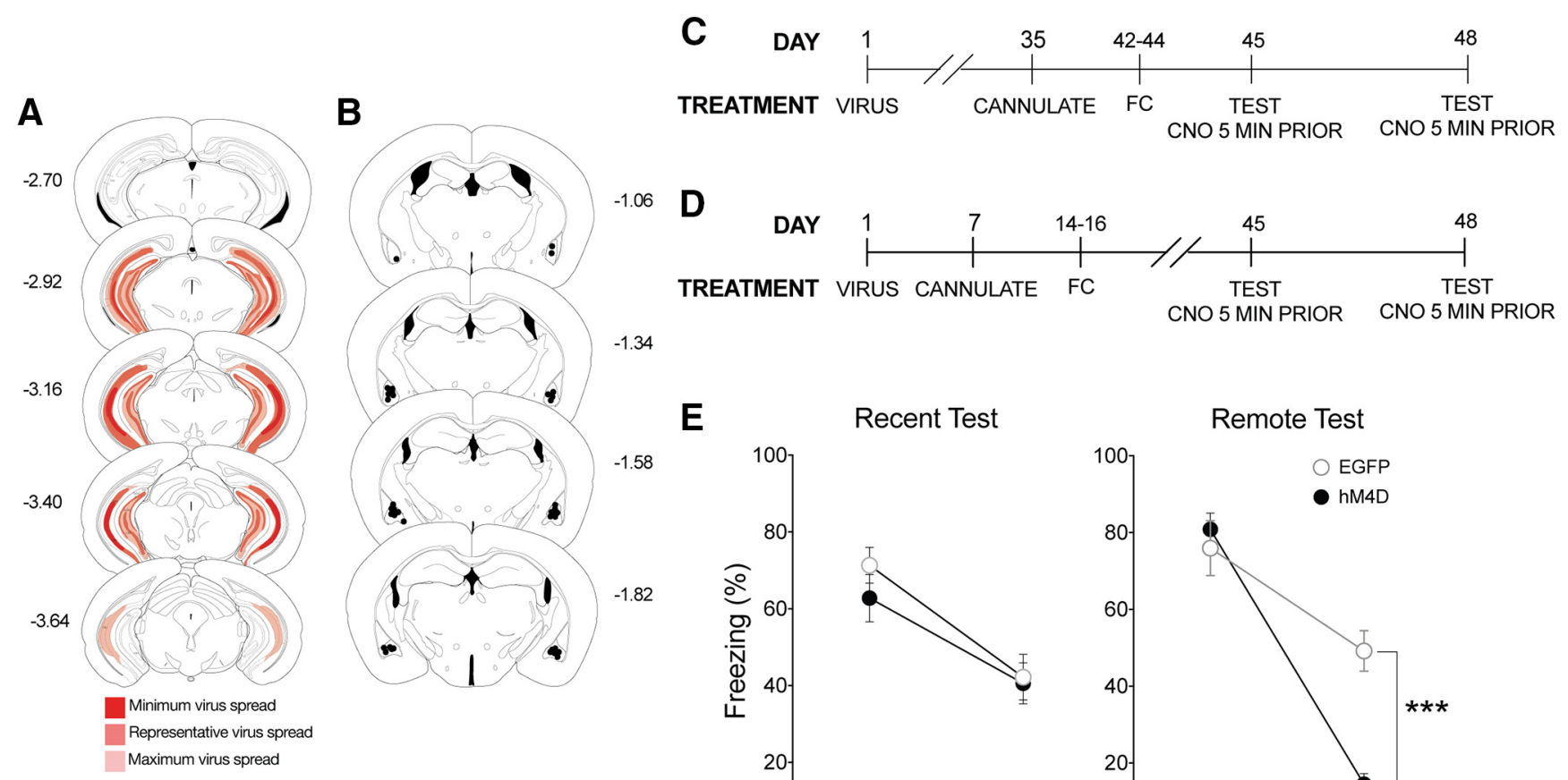

E

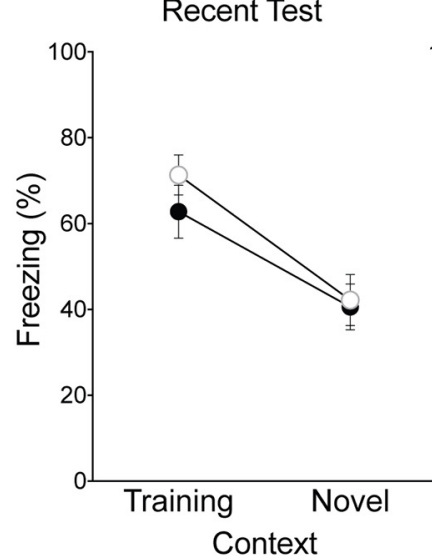

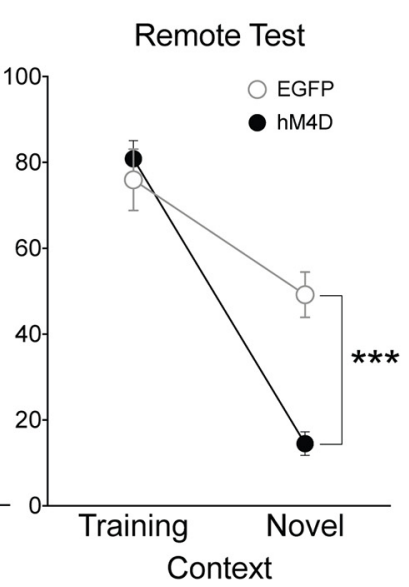

Figure 6. The vHPC coordinates time-dependent generalization. A, As done previously, mice were infused with hM4D or EGFP virus into the vHPC with cannulations targeting the BLA. Viral spread analysis of all hM4D mice tested using a within-subject design with inactivation of BLA terminals identified no expression outside of the vHPC. Dark red represents minimum spread observed and included in analysis. Red represents typical spread observed. Light red represents maximum spread observed and included in behavioral analysis. $\boldsymbol{B}$, Cannulation targets were again analyzed to correct placement into the BLA. There were no missed targets outside of the BLA in this experiment. C, All behavioral tests were completed 7 weeks after viral infusions. Cannulations for the BLA were completed 1 week before behavioral training procedures. In this experiment, rapid generalization was induced using a hybrid mouse line. Mice were tested once in each context at $1 \mathrm{~d}$ or $(\boldsymbol{D}) 28 \mathrm{~d}$ after training with a $72 \mathrm{~h}$ intertest interval. All mice were given a microinfusion of CNO into the BLA 5 min before testing. $E$, Inactivating CaMKIIl $\alpha$ projections from the vHPC to the BLA significantly reduced freezing to the novel context only at the remote test. These data suggest that glutamatergic projections from the VHPC to the BLA selectively control time-dependent generalized fear. Percent freezing levels of EGFP $(O)$ and $\mathrm{hM} 4 \mathrm{D}(-)$ mice during within-subject recent (left) or remote (right) tests in the training and neutral context 5 min after a local infusion of CNO were analyzed ( \pm SEM). A two-way ANOVA identified significant main effects of context at the recent $\left(F_{(1,13)}=19, p<0.001\right)$ and remote tests $\left(F_{(1,9)}=80.9, p<0.001\right)$. After induced generalization, there was a significant interaction only at the remote test $\left(F_{(1,9)}=14.6, p<0.01\right) .{ }^{* * *} p<0.001$.

of our study. Rozeske et al. (2018) found that activation of the projections from the $\mathrm{dmPFC}$, including the infralimbic and prelimbic cortices, and the ACC, to the periaqueductal gray reduced contextual fear generalization, whereas inactivation of these projections increased fear generalization (Rozeske et al., 2018). Much like Xu and Südhof (2013), these studies were not able to differentiate among the three cortices within the dmPFC; transgene expression encompassed most of the mPFC. Thus, the identity of the precise subregion promoting fear generalization via projections to the periaqueductal gray or via additional projections was left unresolved. Here, we selectively targeted the ACC and its projections to the BLA; no transgene expression was observed in the infralimbic or prelimbic cortices, to identify regionspecific control over nonspecific contextual fear.

For decades, the focus of identifying neural mechanisms of fear responding has been the dorsal HPC (dHPC), and much of the current theory is based on experiments within this region (Squire and Alvarez, 1995; Frankland et al., 1998; Teyler and Rudy, 2007; Winocur et al., 2007, 2013; Wiltgen et al., 2010; Hardt et al., 2013). Notably, the experiments described here, and our previous study (Cullen et al., 2015), are the only studies to date examining the role of vHPC in generalized fear responses. Generalized, remote fear responses require the vHPC, whereas the $\mathrm{dHPC}$ is crucial for maintaining specific fear responses (Frankland et al., 1998; Wiltgen et al., 2010; Winocur et al., 2013;
Cullen et al., 2015). Over time, activity of the vHPC and its projections to the BLA exert greater control over generalized fear rather than maintaining control over specific fear, like the dHPC. Our vHPC results also emphasize that there is a dissociation between the roles of the ventral and dHPC in the control of fear processing, an effect that has support from neuroanatomical and connectivity studies (Fanselow and Dong, 2010), but limited systems and behavioral support (Morris, 1981; Maren and Holt, 2004; Hunsaker and Kesner, 2008). The present data also have important implications for predictions that are made by theories about aging fear memories and interactions between the HPC and cortical regions (Squire and Alvarez, 1995; Teyler and Rudy, 2007; Winocur et al., 2007; Hardt et al., 2013).

Systems consolidation hypothesizes that memories stored in the neocortex are identical to those encoded by the HPC and does not address time-dependent changes in memory specificity (Squire and Alvarez, 1995). Our previous (Cullen et al., 2015) and current findings challenge the view that neocortical stored memories are identical to those stored in the HPC. In addition, our data suggest that aged memories continue to be dependent on the HPC, albeit control shifts to the ventral region. Another memory hypothesis suggests that specific memories are initially dependent on the HPC and are transformed to schematic, generalized memories as they are stored in the neocortex, called the transformation hypothesis (Wino- 
cur et al., 2007, 2013), which stems from multiple trace theory (Nadel and Moscovitch, 1997). In the transformation hypothesis, both the schematic memory and the specific memory are continuously accessible; however, specific memories are always dependent on the HPC, whereas generalized memories are dependent on the neocortex as they are transformed over time, independent of the HPC. Therefore, at remote time points, there can be two memory traces and either can be accessed depending on the situational requirements.

Our data challenge the transformation hypothesis' notion that neocortical regions control generalized memories as a function of the training-to-testing interval; our data here show that memories may be immediately stored in a generalized state within the ACC. Experiments using immediate post-training inactivation of the ACC followed by a test for generalization within a novel context are needed to confirm the immediate storage hypothesis. Thus, our current data support the neocortex's involvement in generalized memories, but not that generalized memories are transformed over time, or that they are independent of the HPC.

Studies in full support of the transformation hypothesis thus far have not found evidence for a functional dissociation between the dorsal and vHPC on generalization (Winocur et al., 2007, 2009), suggesting that the HPC, as a whole, is not required for generalized memory recall. Here, we discovered that rapidly generalized memories do not require the vHPC, whereas remote generalized memories do, showing an opposite role of that of the dHPC. Thus, our data, in combination with recent findings (Lynch et al., 2017; Zhou et al., 2017), suggest that transformation of a specific fear memory into a generalized form may actually involve a shift in control over memory recall from the dHPC to the vHPC over time.

Using chemogenetics, we reliably replicated the effects of the ACC and vHPC regulating fear generalization via projections to the BLA; however, there have been recent validity threats to the DREADD system. The DREADD activator, $\mathrm{CNO}$, may be reverse metabolized into clozapine with widespread effects and nonspecific binding of the DREADD receptor (MacLaren et al., 2016; Whissell et al., 2016; Gomez et al., 2017; Manvich et al., 2018). To control for potential off-target effects of $\mathrm{CNO}$, we fearconditioned naive mice and tested them $30 \mathrm{~min}$ after an injection of $\mathrm{CNO}$ or saline. We found no effect of $\mathrm{CNO}$ on contextual fear or the generalization of contextual fear, eliminating the potential confound of CNO specifically for our paradigm. Additionally, intracranial infusions of CNO directly into the BLA replicated the systemic DREADD inactivation findings, and mice expressing hM4D with targets outside the BLA displayed normal freezing behavior in the novel context. Although one study reported offtarget effects with lower a concentration of CNO when locally infused near the hypothalamus (Stachniak et al., 2014), the small volume of the infusions used here $(0.2 \mu \mathrm{l})$ and the lack of any behavioral effect when CNO was infused outside of the BLA strongly suggest that our observed results were not due to offtarget effects of $\mathrm{CNO}$, or its reversal into clozapine, and that the effects were specific to inactivation of axonal projections terminating in the BLA. A few reports suggest that CNO must be first converted into clozapine to cross the blood-brain barrier and exert its effects (Bender et al., 1994; Gomez et al., 2017). Our intra-BLA infusions surpass the blood-brain barrier; therefore, $\mathrm{CNO}$, not clozapine, in Experiments 3, 4, 6, and 7 specifically acted on the DREADD receptors in virally infused mice.

These findings help to uncover part of the neural connectome involved in both specific and general fear responses, which is critical for understanding how humans and nonhumans alike express fearful responses in safe environments (pathological generalization). Clinical research hypothesizes that reduced volume of the ACC and HPC restricts normal inhibitory function on the amygdala leading to increased fear responding (Gurvits et al., 1996; Schuff et al., 2001; Yamasue et al., 2003; Shin et al., 2006; Woodward et al., 2006; Asami et al., 2008; Chen and Etkin, 2013; Greenberg et al., 2013). Our findings confirm that the ACC and HPC, specifically the vHPC, regulate fear in novel, or nonthreatening, environments through their outputs to the amygdala. Furthermore, these regions control generalization in functionally different manners. The ACC time-independently controls generalization, whereas the vHPC plays a strictly time-dependent role in regulating generalized fear. Clinically, these findings implicate that hyperreactive amygdalae in patients with anxiety could be due to an immediate, or potentially preexisting, increase in excitatory signaling from the ACC to the BLA. Later recruitment of excitatory HPC inputs to the BLA may reinforce the preexisting excitation from the ACC and thus contribute to perpetual anxiety. This combination of increased excitatory drive could be the underlying mechanism of nonspecific fear responses associated with anxiety disorders in clinical populations.

\section{References}

Alonso J, Angermeyer MC, Bernert S, Bruffaerts R, Brugha TS, Bryson H, de Girolamo G, Graaf R, Demyttenaere K, Gasquet I, Haro JM, Katz SJ, Kessler RC, Kovess V, Lépine JP, Ormel J, Polidori G, Russo LJ, Vilagut G, Almansa J, et al. (2004) Prevalence of mental disorders in Europe: results from the European Study of the Epidemiology of Mental Disorders (ESEMeD) Project. Acta Psychiatr Scand Suppl 109:21-27.

Armbruster BN, Li X, Pausch MH, Herlitze S, Roth BL (2007) Evolving the lock to fit the key to create a family of $\mathrm{G}$ protein-coupled receptors potently activated by an inert ligand. Proc Natl Acad Sci U S A 104:51635168.

Asami T, Hayano F, Nakamura M, Yamasue H, Uehara K, Otsuka T, Roppongi T, Nihashi N, Inoue T, Hirayasu Y (2008) Anterior cingulate cortex volume reduction in patients with panic disorder. Psychiatr Clin Neurosci 62:322-330

Asok A, Kandel ER, Rayman JB (2018) The neurobiology of fear generalization. Front Behav Neurosci 12:329.

Bender D, Holschbach M, Stöcklin G (1994) Synthesis of n.c.a. carbon-11 labelled clozapine and its major metabolite clozapine-N-oxide and comparison of their biodistribution in mice. Nucl Med Biol 21:921-925.

Campeau S, Davis M (1995) Involvement of subcortical and cortical afferents to the lateral nucleus of the amygdala in fear conditioning measured with fear-potentiated startle in rats trained concurrently with auditory and visual conditioned stimuli. J Neurosci 15:2312-2327.

Cenquizca LA, Swanson LW (2007) Spatial organization of direct hippocampal field CA1 axonal projections to the rest of the cerebral cortex. Brain Res Rev 56:1-26.

Chen AC, Etkin A (2013) Hippocampal network connectivity and activation differentiates post-traumatic stress disorder from generalized anxiety disorder. Neuropsychopharmacology 38:1889-1898.

Cullen PK, Gilman TL, Winiecki P, Riccio DC, Jasnow AM (2015) Activity of the anterior cingulate cortex and ventral hippocampus underlie increases in contextual fear generalization. Neurobiol Learn Mem 124:1927.

Do-Monte FH, Quiñones-Laracuente K, Quirk GJ (2015) A temporal shift in the circuits mediating retrieval of fear memory. Nature 519:460-463.

Dymond S, Dunsmoor JE, Vervliet B, Roche B, Hermans D (2015) Fear generalization in humans: systematic review and implications for anxiety disorder research. Behav Ther 46:561-582.

Einarsson EÖ, Nader K (2012) Involvement of the anterior cingulate cortex in formation, consolidation, and reconsolidation of recent and remote contextual fear memory. Learn Mem 19:449-452.

Einarsson EÖ, Pors J, Nader K (2015) Systems reconsolidation reveals a selective role for the anterior cingulate cortex in generalized contextual fear memory expression. Neuropsychopharmacology 40:480-487.

Fanselow MS, Dong HW (2010) Are the dorsal and ventral hippocampus functionally distinct structures? Neuron 65:7-19. 
Frankland PW, Cestari V, Filipkowski RK, McDonald RJ, Silva AJ (1998) The dorsal hippocampus is essential for context discrimination but not for contextual conditioning. Behav Neurosci 112:863-874.

Frankland PW, Bontempi B, Talton LE, Kaczmarek L, Silva AJ (2004a) The involvement of the anterior cingulate cortex in remote contextual fear memory. Science 304:881-883.

Frankland PW, Josselyn SA, Anagnostaras SG, Kogan JH, Takahashi E, Silva AJ (2004b) Consolidation of CS and US representations in associative fear conditioning. Hippocampus 14:557-569.

Gomez JL, Bonaventura J, Lesniak W, Mathews WB, Sysa-Shah P, Rodriguez LA, Ellis RJ, Richie CT, Harvey BK, Dannals RF, Pomper MG, Bonci A, Michaelides M (2017) Chemogenetics revealed: DREADD occupancy and activation via converted clozapine. Science 357:503-507.

Goshen I, Brodsky M, Prakash R, Wallace J, Gradinaru V, Ramakrishnan C, Deisseroth K (2011) Dynamics of retrieval strategies for remote memories. Cell 147:678-689.

Greenberg T, Carlson JM, Cha J, Hajcak G, Mujica-Parodi LR (2013) Ventromedial prefrontal cortex reactivity is altered in generalized anxiety disorder during fear generalization. Depress Anxiety 30:242-250.

Gurvits TV, Shenton ME, Hokama H, Ohta H, Lasko NB, Gilbertson MW, Orr SP, Kikinis R, Jolesz FA, McCarley RW, Pitman RK (1996) Magnetic resonance imaging study of hippocampal volume in chronic, combatrelated posttraumatic stress disorder. Biol Psychiatry 40:1091-1099.

Hardt O, Nader K, Nadel L (2013) Decay happens: the role of active forgetting in memory. Trends Cogn Sci 17:109-118.

Hefner K, Whittle N, Juhasz J, Norcross M, Karlsson RM, Saksida LM, Bussey TJ, Singewald N, Holmes A (2008) Impaired fear extinction learning and cortico-amygdala circuit abnormalities in a common genetic mouse strain. J Neurosci 28:8074-8085.

Huff ML, Emmons EB, Narayanan NS, LaLumiere RT (2016) Basolateral amygdala projections to ventral hippocampus modulate the consolidation of footshock, but not contextual, learning in rats. Learn Mem 23:5160.

Hunsaker MR, Kesner RP (2008) Dissociations across the dorsal-ventral axis of CA3 and CA1 for encoding and retrieval of contextual and auditory-cued fear. Neurobiol Learn Mem 89:61-69.

Jasnow AM, Cullen PK, Riccio DC (2012) Remembering another aspect of forgetting. Front Psychol 3:175.

Jasnow AM, Lynch JF 3rd, Gilman TL, Riccio DC (2017) Perspectives on fear generalization and its implications for emotional disorders. J Neurosci Res 95:821-835.

Jendryka M, Palchaudhuri M, Ursu D, van der Veen B, Liss B, Kätzel D, Nissen W, Pekcec A (2019) Pharmacokinetic and pharmacodynamic actions of clozapine-N-oxide, clozapine, and compound 21 in DREADDbased chemogenetics in mice. Sci Rep 9:4522.

Kessler RC, Petukhova M, Sampson NA, Zaslavsky AM, Wittchen HU (2012) Twelve-month and lifetime prevalence and lifetime morbid risk of anxiety and mood disorders in the United States. Int J Methods Psychiatr Res 21:169-184.

Kim JJ, Fanselow MS (1992) Modality-specific retrograde amnesia of fear. Science 256:675-677.

Kim JJ, Rison RA, Fanselow MS (1993) Effects of amygdala, hippocampus, and periaqueductal gray lesions on short- and long-term contextual fear. Behav Neurosci 107:1093-1098.

Lissek S, Powers AS, McClure EB, Phelps EA, Woldehawariat G, Grillon C, Pine DS (2005) Classical fear conditioning in the anxiety disorders: a meta-analysis. Behav Res Ther 43:1391-1424.

Lissek S, Rabin S, Heller RE, Lukenbaugh D, Geraci M, Pine DS, Grillon C (2010) Overgeneralization of conditioned fear as a pathogenic marker of panic disorder. Am J Psychiatry 167:47-55.

Lynch JF, Winiecki P, Gilman TL, Adkins JM, Jasnow AM (2017) Hippocampal $\operatorname{GABAB}(1 \mathrm{a})$ receptors constrain generalized contextual fear. Neuropsychopharmacology 42:914-924.

MacLaren DA, Browne RW, Shaw JK, Krishnan Radhakrishnan S, Khare P, España RA, Clark SD (2016) Clozapine N-oxide administration produces behavioral effects in Long-Evans rats: implications for designing DREADD experiments. eNeuro 3:ENEURO.0219-16.2016.

Mahler SV, Vazey EM, Beckley JT, Keistler CR, McGlinchey EM, Kaufling J, Wilson SP, Deisseroth K, Woodward JJ, Aston-Jones G (2014) Designer receptors show role for ventral pallidum input to ventral tegmental area in cocaine seeking. Nat Neurosci 17:577-585.

Manvich DF, Webster KA, Foster SL, Farrell MS, Ritchie JC, Porter JH, Wein- shenker D (2018) The DREADD agonist clozapine N-oxide (CNO) is reverse-metabolized to clozapine and produces clozapine-like interoceptive stimulus effects in rats and mice. Sci Rep 8:3840.

Maren S, Fanselow MS (1995) Synaptic plasticity in the basolateral amygdala induced by hippocampal formation stimulation in vivo. J Neurosci 15:7548-7564.

Maren S, Holt WG (2004) Hippocampus and Pavlovian fear conditioning in rats: muscimol infusions into the ventral, but not dorsal, hippocampus impair the acquisition of conditional freezing to an auditory conditional stimulus. Behav Neurosci 118:97-110.

Maren S, Aharonov G, Stote DL, Fanselow MS (1996) N-methyl-Daspartate receptors in the basolateral amygdala are required for both acquisition and expression of conditional fear in rats. Behav Neurosci 110:1365-1374.

McCullough KM, Morrison FG, Ressler KJ (2016) Bridging the gap: towards a cell-type specific understanding of neural circuits underlying fear behaviors. Neurobiol Learn Mem 135:27-39.

Morey RA, Dunsmoor JE, Haswell CC, Brown VM, Vora A, Weiner J, Stjepanovic D, Wagner HR 3rd, LaBar KS (2015) Fear learning circuitry is biased toward generalization of fear associations in posttraumatic stress disorder. Transl Psychiatry 5:e700.

Morozov A, Sukato D, Ito W (2011) Selective suppression of plasticity in amygdala inputs from temporal association cortex by the external capsule. J Neurosci 31:339-345.

Morris RG (1981) Spatial localization does not require the presence of local cues. Learn Motiv 12:239-260.

Nadel L, Moscovitch M (1997) Memory consolidation, retrograde amnesia and the hippocampal complex. Curr Opin Neurobiol 7:217-227.

Rozeske RR, Jercog D, Karalis N, Chaudun F, Khoder S, Girard D, Winke N, Herry C (2018) Prefrontal-periaqueductal gray-projecting neurons mediate context fear discrimination. Neuron 97:898-910.e6.

Schafe GE, Doyère V, LeDoux JE (2005) Tracking the fear engram: the lateral amygdala is an essential locus of fear memory storage. J Neurosci 25:10010-10014.

Schuff N, Neylan TC, Lenoci MA, Du AT, Weiss DS, Marmar CR, Weiner MW (2001) Decreased hippocampal N-acetylaspartate in the absence of atrophy in posttraumatic stress disorder. Biol Psychiatry 50:952-959.

Scofield MD, Boger HA, Smith RJ, Li H, Haydon PG, Kalivas PW (2015) Gq-DREADD selectively initiates glial glutamate release and inhibits cueinduced cocaine seeking. Biol Psychiatry 78:441-451.

Shin LM, Orr SP, Carson MA, Rauch SL, Macklin ML, Lasko NB, Peters PM, Metzger LJ, Dougherty DD, Cannistraro PA, Alpert NM, Fischman AJ, Pitman RK (2004) Regional cerebral blood flow in the amygdala and medial prefrontal cortex during traumatic imagery in male and female Vietnam veterans with PTSD. Arch Gen Psychiatry 61:168-176.

Shin LM, Rauch SL, Pitman RK (2006) Amygdala, medial prefrontal cortex, and hippocampal function in PTSD. Ann N Y Acad Sci 1071:67-79.

Smith DR, Gallagher M, Stanton ME (2007) Genetic background differences and nonassociative effects in mouse trace fear conditioning. Learn Mem 14:597-605.

Squire LR, Alvarez P (1995) Retrograde amnesia and memory consolidation: a neurobiological perspective. Curr Opin Neurobiol 5:169-177.

Stachniak TJ, Ghosh A, Sternson SM (2014) Chemogenetic synaptic silencing of neural circuits localizes a hypothalamus $\rightarrow$ midbrain pathway for feeding behavior. Neuron 82:797-808.

Tanaka KZ, Pevzner A, Hamidi AB, Nakazawa Y, Graham J, Wiltgen BJ (2014) Cortical representations are reinstated by the hippocampus during memory retrieval. Neuron 84:347-354.

Teyler TJ, Rudy JW (2007) The hippocampal indexing theory and episodic memory: updating the index. Hippocampus 17:1158-1169.

Vazey EM, Aston-Jones G (2014) Designer receptor manipulations reveal a role of the locus coeruleus noradrenergic system in isoflurane general anesthesia. Proc Natl Acad Sci U S A 111:3859-3864.

Whissell PD, Tohyama S, Martin LJ (2016) The use of DREADDs to deconstruct behavior. Front Genet 7:70.

Wiltgen BJ, Silva AJ (2007) Memory for context becomes less specific with time. Learn Mem 14:313-317.

Wiltgen BJ, Zhou M, Cai Y, Balaji J, Karlsson MG, Parivash SN, Li W, Silva AJ (2010) The hippocampus plays a selective role in the retrieval of detailed contextual memories. Curr Biol 20:1336-1344.

Winocur G, Moscovitch M, Sekeres M (2007) Memory consolidation or 
transformation: context manipulation and hippocampal representations of memory. Nat Neurosci 10:555-557.

Winocur G, Frankland PW, Sekeres M, Fogel S, Moscovitch M (2009) Changes in context-specificity during memory reconsolidation: selective effects of hippocampal lesions. Learn Mem 16:722-729.

Winocur G, Sekeres MJ, Binns MA, Moscovitch M (2013) Hippocampal lesions produce both nongraded and temporally graded retrograde amnesia in the same rat. Hippocampus 23:330-341.

Woodward SH, Kaloupek DG, Streeter CC, Martinez C, Schaer M, Eliez S (2006) Decreased anterior cingulate volume in combat-related PTSD. Biol Psychiatry 59:582-587.

Xu W, Südhof TC (2013) A neural circuit for memory specificity and generalization. Science 339:1290-1295.
Yamasue H, Kasai K, Iwanami A, Ohtani T, Yamada H, Abe O, Kuroki N, Fukuda R, Tochigi M, Furukawa S, Sadamatsu M, Sasaki T, Aoki S, Ohtomo K, Asukai N, Kato N (2003) Voxel-based analysis of MRI reveals anterior cingulate gray-matter volume reduction in posttraumatic stress disorder due to terrorism. Proc Natl Acad Sci U S A 100:9039-9043.

Zhou H, Xiong GJ, Jing L, Song NN, Pu DL, Tang X, He XB, Xu FQ, Huang JF, Li LJ, Richter-Levin G, Mao RR, Zhou QX, Ding YQ, Xu L (2017) The interhemispheric CA1 circuit governs rapid generalisation but not fear memory. Nat Commun 8:2190.

Zola-Morgan SM, Squire LR (1990) The primate hippocampal formation: evidence for a time-limited role in memory storage. Science 250: $288-290$. 